\title{
NADPH oxidase in brain injury and neurodegenerative disorders
}

\author{
Merry W. Ma ${ }^{1,2}$, Jing Wang ${ }^{1,2}$, Quanguang Zhang ${ }^{1,2}$, Ruimin Wang ${ }^{1,2}$, Krishnan M. Dhandapani ${ }^{1,3}$, \\ Ratna K. Vadlamudi ${ }^{4}$ and Darrell W. Brann ${ }^{1,2^{*}}$
}

\begin{abstract}
Oxidative stress is a common denominator in the pathology of neurodegenerative disorders such as Alzheimer's disease, Parkinson's disease, Huntington's disease, amyotrophic lateral sclerosis, and multiple sclerosis, as well as in ischemic and traumatic brain injury. The brain is highly vulnerable to oxidative damage due to its high metabolic demand. However, therapies attempting to scavenge free radicals have shown little success. By shifting the focus to inhibit the generation of damaging free radicals, recent studies have identified NADPH oxidase as a major contributor to disease pathology. NADPH oxidase has the primary function to generate free radicals. In particular, there is growing evidence that the isoforms NOX1, NOX2, and NOX4 can be upregulated by a variety of neurodegenerative factors. The majority of recent studies have shown that genetic and pharmacological inhibition of NADPH oxidase enzymes are neuroprotective and able to reduce detrimental aspects of pathology following ischemic and traumatic brain injury, as well as in chronic neurodegenerative disorders. This review aims to summarize evidence supporting the role of NADPH oxidase in the pathology of these neurological disorders, explores pharmacological strategies of targeting this major oxidative stress pathway, and outlines obstacles that need to be overcome for successful translation of these therapies to the clinic.
\end{abstract}

Keywords: NADPH oxidase, Alzheimer's disease, Stroke, Neurodegeneration, Oxidative stress, Traumatic brain injury, Parkinson's disease, Amyotrophic lateral sclerosis, Huntington's disease, Multiple sclerosis

\section{Background}

Neurodegenerative disorders such as stroke, traumatic brain injury (TBI), Alzheimer's disease (AD), Parkinson's disease (PD), Huntington's disease (HD), amyotrophic lateral sclerosis (ALS), and multiple sclerosis (MS) carry substantial disease burden, not only in terms of health suffering but also in economic costs [1-6]. Although the clinical manifestations differ for these disorders, a common denominator in their pathology is the induction of oxidative stress $[7,8]$. For the past several decades, evidence has accumulated supporting oxidative stress as an underlying common denominator of brain injury and neurodegenerative disorders. For instance, a keyword search on PubMed using the terms "oxidative stress and neurodegeneration" or "oxidative stress and brain injury"

\footnotetext{
* Correspondence: dbrann@augusta.edu

${ }^{1}$ Charlie Norwood VA Medical Center, One Freedom Way, Augusta, GA 30904, USA

${ }^{2}$ Department of Neuroscience and Regenerative Medicine, Medical College of Georgia, 1120 Fifteenth Street, Augusta, GA 30912, USA

Full list of author information is available at the end of the article
}

yielded over 8,400 citations, with approximately half of these occurring in the last five years. From this body of research, it has become clear that pathological conditions such as ischemia, trauma, and neurodegenerative processes, markedly enhances generation of ROS in the brain $[9,10]$. Therapies attempting to target oxidative stress have typically focused on compounds that scavenge the free radicals to eliminate them from the system. Unfortunately, these therapies have generally been unsuccessful in clinical trials despite promise in animal models.

The lack of success to date of clinical trials using ROS scavenging drugs has led to the hypothesis that inhibition of the generation, rather than the scavenging, of ROS may be a more successful avenue of therapy. Correlative to this hypothesis, many laboratories have focused on enhancing our understanding of the role of ROS-generating pathways in various pathological situations. These studies have led to the identification of the enzyme, nicotinamide adenine dinucleotide phosphate 
(NADPH) oxidase as a major generator of ROS that contributes to the pathology of both acute brain injury and chronic neurodegenerative disorders [11, 12]. While NADPH oxidase undoubtedly contributes to physiological processes in the brain [13, 14], the primary goal of the current review is to summarize the evidence supporting a role of NADPH oxidase following acute ischemic and traumatic brain injury, as well as in chronic neurodegenerative disorders, and explore the potential efficacy and strategies for therapeutic targeting of this major ROS-generating pathway.
Origin and cellular consequence of oxidative stress in brain injury and neurodegenerative disorders

ROS are generated endogenously from molecular oxygen by cellular oxidases, mono- and di-oxygenases of the mitochondrial electron chain transport system, or peroxidases. The major ROS involved in oxidative stress include superoxide anion, hydrogen peroxide, and hydroxyl radicals [15]. There are also reactive nitrogen species (RNS) such as nitric oxide and peroxynitrite that participate in oxidative stress in the CNS and throughout the body $[10,16]$. As shown in Fig. 1a, there are multiple sources

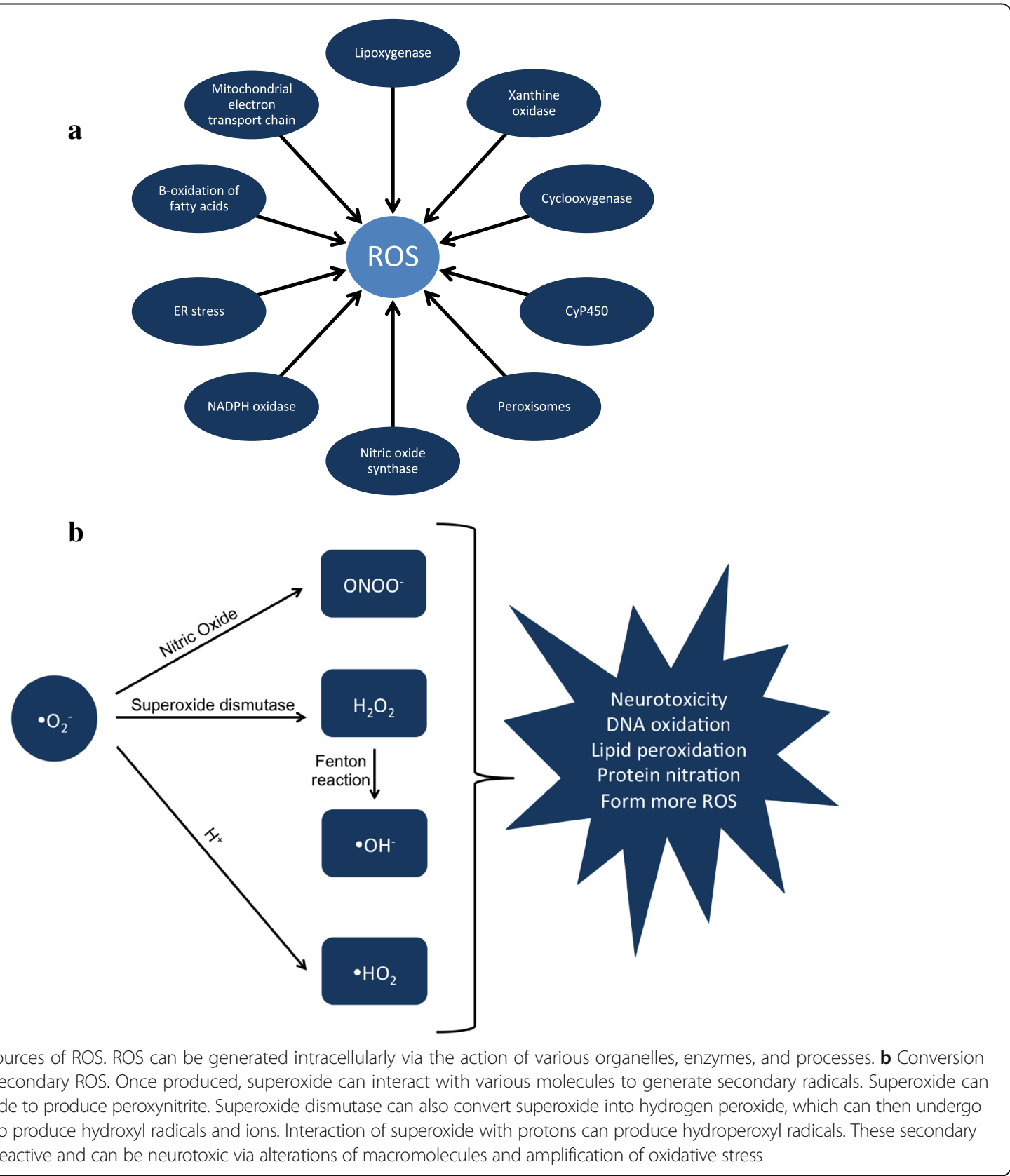


and processes that lead to generation of superoxide and ROS in cells. Superoxide, once produced, can cause oxidative damage directly, or it can interact with other molecules to generate "secondary" radicals via enzymatic or metal-catalyzed reactions. Along these lines, as shown in Fig. 1b, superoxide can react with nitric oxide to generate the RNS peroxynitrite, which is highly reactive, and when over-produced can deleteriously nitrate most biological molecules in all parts of the body, including the brain $[16,17]$. Superoxide can also undergo dismutation via superoxide dismutase to form oxygen and hydrogen peroxide [18]. Hydrogen peroxide is highly permeable through cell membranes and can directly damage cells through oxidation of deoxyribonucleic acid (DNA), proteins, and lipids. In the presence of transition metals, hydrogen peroxide can generate highly reactive hydroxyl radicals, which can damage DNA and other molecules in the cell $[19,20]$. In addition to modifying and damaging macromolecules, the unpaired electron in ROS can also amplify oxidative damage by generating more free radicals [21]. Finally, ROS-induced modifications can target cysteine residues or oxidize thiols present in protein components of cell signaling [22], and this alteration in signaling can lead to a variety of downstream effects involving gene expression and apoptosis.

The relationship between the cellular consequences of oxidative stress and the progression of brain injury and neurodegenerative disorders has undergone continued refinement. Extensive research has shown that mitochondria-derived ROS are clinically relevant as an important contributing factor for neurodegeneration in brain injury and chronic neurodegenerative disorders. While coverage of this topic is beyond the scope of this review, the reader is referred to several excellent reviews written previously on this subject [23-26]. Recently, there has been increased interest in other sources of ROS, such as NADPH oxidase, nitric oxide synthase, cytochrome450 (cyp450), cyclooxygenase, lipooxygenase, and xanthine oxidase $[19,27]$. Of the above list, only NADPH oxidase has as its primary function the generation of ROS, as the others generate ROS as a byproduct [28-30]. Previous reviews have summarized evidence of redox crosstalk between mitochondria and NADPH oxidase that suggests mitochondria may be a key player and trigger in amplifying the burden of oxidative stress [31-33]. In the sections below, we will focus upon evidence concerning the biology, distribution and role of the various NADPH oxidase family members in brain injury and neurodegenerative disorders.

\section{NADPH oxidase - an overview}

The NADPH oxidase (NOX) family of enzymes are transmembrane carriers that transport an electron from cytosolic NADPH to reduce oxygen to superoxide anion [12].
To date, there are seven known members which combine with various subunits to form active enzyme complexes NOX1, NOX2, NOX3, NOX4, NOX5, dual oxidase 1 (DUOX1), and DUOX2 [34-37] (Fig. 2). The NOX and DUOX isoforms are structurally similar with each isoform having binding sites for heme, flavin adenine dinucleotide (FAD) and NADPH [38, 39], and 6 conserved transmembrane $\alpha$-helices [12]. DUOX enzymes have an additional seventh transmembrane helix and possess peroxidase activity [12]. Once the active complex is assembled, an electron from cytosolic NADPH is transferred to oxygen on the extracellular side [12]. The distribution and regulation of the NOX and DUOX isoforms throughout the body and brain varies depending upon the isoform. Table 1 summarizes the reported distribution of NOX and DUOX isoforms throughout the body, including the central nervous system (CNS). It also lists the major corresponding regulators and products for the various isoforms.

\section{NOX1}

NOX1 generates the product superoxide, and has the most similarity to the NOX2 and NOX3 isoforms, as evidenced by association with homologous regulatory subunits and regulation by Rac GTPase [40-42]. As shown in Fig. 2, NOX1-3 subunits form functional dimers with p22phox. In addition, NADPH oxidase activator 1 (NOXA1) serves as an "activator" for NOX 1 and 3 [43], and is structurally homologous to p67 phagocytic oxidase (p67phox), which is the activator for NOX2. NADPH oxidase organizer 1 (NOXO1) is an "organizer" for NOX1 and $3[43,44]$, and is structurally homologous to p47phox and p40phox, which are organizers for NOX2. Superoxide anion production by NOX1 has been shown to require phosphorylation of NOXO1 by protein kinase A (PKA) (at Ser154) or PKC (at Thr341), which then interacts with NOXA1 to regulate NOX1 activity [45]. However, it is important to note that NOXO1 is localized at the membrane independent of cellular activation, which combined with its lack of auto-inhibitory function, may contribute to constitutively activated NOX1 [44]. Additional work has shown that phosphorylation of NOXA1 on serine 282 by MAP kinases and on serine 172 by PKC down-regulates constitutive NOX1 activity [46]. In addition, phosphorylation of NOX1 (at Thr429) by PKC- $\beta$ has been reported to be critical for NOX1 complex formation with the cytosolic regulatory units and thus for NOX1 activation [47, 48]. Furthermore, as shown in Fig. 2, Rac1 is also a known activator of NOX1 [41]. Finally, a number of enzymes, cytokines, growth factors, hormones, and cell stressors have been implicated to also regulate NOX1 [49-60]. Functionally, NOX1 has been implicated in pain that accompanies inflammation, host defense via expression in microglia, and neuronal growth [61-64]. A role for NOX1 in 


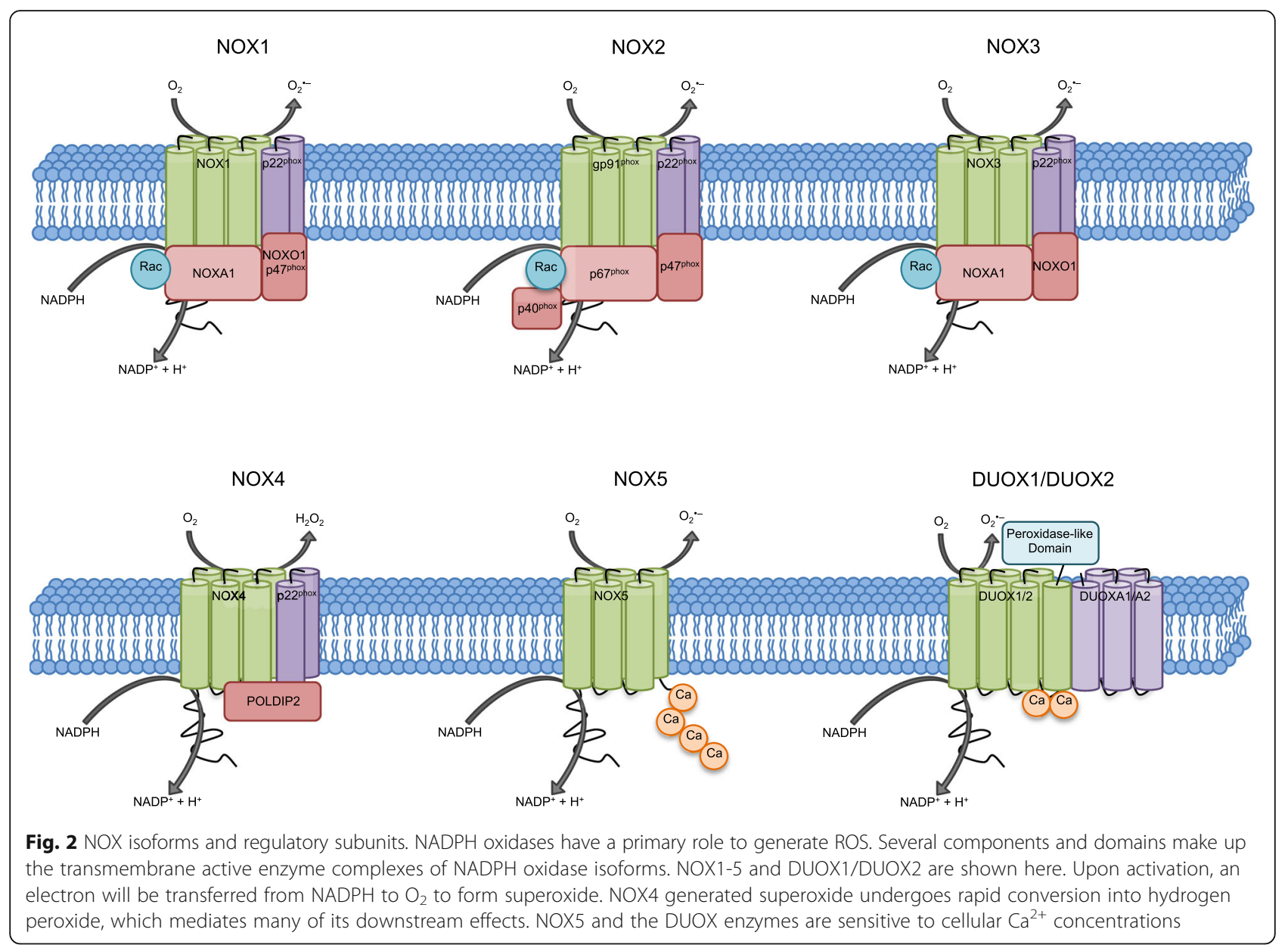

neuropathology and neurodegenerative disorders has also been implicated and will be discussed in subsequent sections below.

\section{NOX2}

NOX2 (sometimes referred to by its major subunit name - gp91phox) generates superoxide as its product $[12,65,66]$. NOX2 is expressed in various tissues of the body as well as several regions of the brain (see Table 1). At the cellular level, NOX2 has been reported to be expressed in various cell types, including neurons and endothelial cells [67-69], and is heavily expressed in microglia, where it is involved in immune/inflammatory responses [70], particularly after injury [71, 72]. As shown in Fig. 2, NOX2 has both membrane subunits (gp91phox and p22phox) and cytosolic components (p47phox and p67phox). During activation, a phosphorylated p47phox interacts with p22phox, which facilitates translocation to the membrane where p67phox can bind to p47phox to form the active NOX2 complex [73-75]. Rac2 is coordinately recruited to the membrane, where it binds directly to p67phox and is essential for NOX2 activation [76, 77]. Binding sites for Rac2 have also been identified directly in
NOX2 [78]. NOX2 in non-phagocytic cells is structurally similar to NOX2 of phagocytes, but its regulation may differ. A resting endothelial cell has partially preassembled NOX2 that generates low levels of superoxide intracellularly for physiological functions rather than having functional activity bound to the plasma membrane such as in neutrophils [79]. Activation of NOX2 requires serine phosphorylation of the p47phox subunit in models using TNF stimulation $[80,81]$ and angiotensin II stimulation [82]. Furthermore, a number of enzymes, cytokines, metabolic factors, and cell stressors (hypoxia and $A \beta$ ) have been implicated to regulate NOX2 [53, 68, 83-89]. Identified downstream targets of NOX2-derived ROS include various kinase signaling pathways [90-95], as well as cytokines and transcription factors [80, 96-99].

\section{NOX3}

In the brain, NOX3 has been reported to be expressed in neurons in the inner ear [71], where it has been implicated to play a significant role in the cochlea and vestibular system [12, 100, 101]. In support of this contention, NOX3 knockout mice have been reported to show signs of imbalance [102]. In addition, reduction of NOX3 has 
Table 1 Tissue and cellular distribution of NOX isoforms

\begin{tabular}{|c|c|c|c|c|}
\hline ISOFORM & Regulators & Product & Reported Non-CNS Distribution & CNS tissue \\
\hline NOX1 & $\begin{array}{l}\text { NOXO1 } \\
\text { NOXA1 } \\
\text { Rac1 } \\
\text { PKA } \\
\text { PKC } \\
\text { MAPK } \\
\text { Hsp90 }\end{array}$ & Superoxide & $\begin{array}{l}\text { Colon }[35,39,42] \\
\text { Blood vessels [70, 359, 360] } \\
\text { Heart [361] } \\
\text { Bone marrow [362] } \\
\text { Cochlea [103] }\end{array}$ & $\begin{array}{l}\text { Cerebral cortex }[53,139] \\
\text { Hippocampus }[50,202] \\
\text { Cerebellum }[363] \\
\text { Substantia nigra }[364] \\
\text { Striatum }[61] \\
\text { Hypothalamus }[361] \\
\text { Cerebral vessels }[359,365]\end{array}$ \\
\hline $\mathrm{NOX} 2$ & $\begin{array}{l}\text { P67phox } \\
\text { P47phox } \\
\text { P40phox } \\
\text { Rac } \\
\text { Hsp90 }\end{array}$ & Superoxide & $\begin{array}{l}\text { Vasculature [365, 366] } \\
\text { Phagocytes [319,367] } \\
\text { Heart [361, 368, 369] } \\
\text { Kidney [370] } \\
\text { Gastrointestinal tract [371] } \\
\text { Liver [372] } \\
\text { Pancreas [373] } \\
\text { Cochlea [103] }\end{array}$ & $\begin{array}{l}\text { Cerebral cortex [71, 374, 375] } \\
\text { Hippocampus [132, 374, 376] } \\
\text { Cerebellum [363] } \\
\text { Striatum [377, 378] } \\
\text { Substantia nigra [379, 380] } \\
\text { Hypothalamus [361, 381] } \\
\text { Subfornical organ [382] } \\
\text { Lateral ventricle [383] } \\
\text { Subventricular zone [383] } \\
\text { Midbrain [380] } \\
\text { Nucleus tractus solitarius [384] }\end{array}$ \\
\hline NOX3 & $\begin{array}{l}\text { NOXA1 } \\
\text { NOXO1 } \\
\text { Rac } \\
\text { p67phox }\end{array}$ & Superoxide & $\begin{array}{l}\text { Inner ear/Cochlea }[100,102,103,385] \\
\text { Lungs }[386,387]\end{array}$ & Cerebral cortex [71] \\
\hline NOX4 & $\begin{array}{l}\text { p22 } \\
\text { PolDipox } \\
\text { PDI } \\
\text { Hypoxia } \\
\text { mGlu3 } \\
\text { PI3K } \\
\text { TLR4 }\end{array}$ & Hydrogen peroxide & $\begin{array}{l}\text { Ubiquitous, including: } \\
\text { Kidney }[35,39,388] \\
\text { Vessels }[389,390] \\
\text { Lung }[391-394] \\
\text { Bone }[39,362,395] \\
\text { Placenta }[35,39,396] \\
\text { Cochlea }[103]\end{array}$ & $\begin{array}{l}\text { Cerebral cortex [71, 377, 397] } \\
\text { Hippocampus [376] } \\
\text { Cerebellum [363] } \\
\text { Hypothalamus [361, 381, 398] } \\
\text { Subfornical organ [382] } \\
\text { Glioblastoma [35] }\end{array}$ \\
\hline NOX5 & $\begin{array}{l}\mathrm{Ca}^{+2} \\
\mathrm{Hsp} 90\end{array}$ & Superoxide & $\begin{array}{l}\text { Testis [35] } \\
\text { Ovary [35] } \\
\text { Spleen [35] } \\
\text { Kidney [399] } \\
\text { Vasculature [400, 401] } \\
\text { Uterus [402] } \\
\text { Cochlea [103] } \\
\text { Tumors }[35,115]\end{array}$ & Glioblastoma $[35,116]$ \\
\hline DUOX1 & $\begin{array}{l}\mathrm{Ca}^{2+} \\
\text { Duoxa1 } \\
\text { Duoxa2 }\end{array}$ & Hydrogen peroxide & $\begin{array}{l}\text { Thyroid }[34,37] \\
\text { Lung }[354,403,404] \\
\text { Skin }[154,156,405] \\
\text { Cochlea }[103]\end{array}$ & None reported \\
\hline DUOX2 & $\begin{array}{l}\mathrm{Ca}^{2+} \\
\text { TRIF/NFkB } \\
\text { MyD88/p38 } \\
\text { Duoxa1 } \\
\text { Duoxa2 }\end{array}$ & Hydrogen peroxide & $\begin{array}{l}\text { Cochlea }[103] \\
\text { Thyroid }[34,37] \\
\text { Lung }[125,354] \\
\text { Gl tract }[152,403,406] \\
\text { Salivary gland }[403]\end{array}$ & None reported \\
\hline
\end{tabular}

been implicated to have a protective effect in cochlear injury by reducing the amount of oxidative stress produced [103]. NOX3 generates superoxide as its product, and the regulatory mechanism of NOX3 can involve Rac1, NOXO1, and p67phox [40, 64, 104]. Furthermore, it has been suggested that the p22phox subunit is critical for the proper assembly and function of NOX3 $[105,106]$ (see Fig. 2 and Table 1). Finally, NOX3 has also been reported to be active in absence of its known regulators [104].

\section{NOX4}

NOX4 is a constitutively activated isoform [107, 108], whose expression however is inducible. Unlike the other
NOX isoforms, the downstream effects of NOX4 are thought to be mediated by hydrogen peroxide, due to the rapid conversion of NOX4-generated superoxide to hydrogen peroxide [109]. As shown in Table 1, NOX4 is widely expressed in the body, and is expressed in various brain regions and cells. It is reported to be a major source of superoxide in human pericytes [110]. NOX4 requires the p22phox subunit for function [108] and has been suggested to be inducible due to the close association between NOX4 mRNA and ROS generation [109]. In addition, other NOX4 regulatory proteins have been identified (Table 1), such as polymerase (DNA-directed) delta interacting protein 2 (Poldip2) [111], protein 
disulfide isomerase (PDI) [112], and tyrosine kinase substrate with 4/5 SH3 domains (Tsks4/5) [113], which may further regulate the activity of NOX4. In addition, recent evidence suggests that hydrogen peroxide-inducible clone 5 (Hic-5), a focal adhesion adaptor protein, functions as a negative regulator of NOX4 by promoting the ubiquitin-proteosomal system-mediated degradation of NOX4 [114].

\section{NOX5}

First reported in 2001, NOX5 is genetically the most distinct of the NOX isoforms [35, 115]. As shown in Table 1, NOX5 is highly expressed in the spleen and testis, and to a lesser extent in other tissues of the body. Expression of NOX5 in the brain has only been documented in brain cancer, specifically glioblastoma multiforme [116]. As shown in Fig. 2, NOX5 is distinct from the other NOX isoforms in that it forms fully functional oligomers [117]. Finally, phosphorylation of NOX5 on Thr494 and Ser498 residue has been reported to increase its sensitivity to calcium [118].

\section{DUOX1/2}

Dual oxidases one and two (DUOX1/2) generate hydrogen peroxide, and are named for their gp91phox domain and their extracellular peroxidase domain. DUOX1 and DUOX2 have been most studied in the thyroid [34, 37], but have also been found in other parts of the body (see Table 1). As shown in Fig. 2, DUOX enzymes interact with DUOX activator proteins, DUOXA1 and DUOXA2, which are critical for targeting and function of the DUOX enzymes [119]. DUOX2 is reported to be involved in thyroid hormone synthesis, and missense mutation of DUOX2 results in congenital hypothyroidism [120]. DUOX1 is also expressed in the thyroid gland, but its function in the thyroid is unknown. Recently, investigations on the DUOX enzymes have expanded to other body systems. DUOX1 has been reported to mediate allergic asthma [121], prolong ROS generation after irradiation [122], and play a role in cancer development [123]. DUOX2 has been reported to mediate keratinocyte inflammation [124], cochlear injury [103], and lung injury [125]. Furthermore, both DUOX enzymes have been implicated to be important in ROS-dependent immunity [126].

\section{Evidence of a role of NADPH oxidase in brain injury and neurodegenerative disorders}

There is growing evidence of a role of NOX isoforms in brain injury and neurodegenerative disorders, particularly for NOX1, 2, and 4. NOX activation can be increased by a variety of inflammatory and neurodegenerative factors, such as amyloid precursor protein (APP), amyloid $\beta$, tumor necrosis factor-alpha (TNF- $\alpha)$, matrix metalloproteinase
(MMP), interleukins, and $\alpha$-synucleins, as well as neuronal damage and cell death $[75,80,127,128]$. Evidence supporting a role of NOX activation in the pathology of ischemic and traumatic brain injury, as well as several major neurodegenerative disorders is discussed in detail below. Table 2 summarizes animal studies showing effects of genetic deletion or knockdown of NOX in the following disease models.

\section{Stroke}

NOX activation in stroke Tissue injury in stroke is caused paradoxically by both the depletion of oxygen (ischemia) and the replenishment of oxygen (reperfusion). Increased levels of ROS have been proposed to have clinical significance in both stages of stroke injury $[129,130]$. Furthermore, there is considerable evidence that NOX-mediated ROS is a major mechanism of neuronal damage in stroke pathology [12, 131-133]. To date, NOX2 and NOX4 are the isoforms most implicated to contribute to ROS generation and pathology following cerebral ischemia, although there is also some evidence for NOX1 involvement as well. Both focal and global cerebral ischemia models have been used in the study of NOX activation. Using a transient global cerebral ischemia (tGCI) model, our group reported a 6-7 fold elevation of NOX2 (gp91phox) membrane complex formation, NADPH oxidase activity, and superoxide production in the hippocampus after tGCI [132]. Additional studies revealed that NOX2 is primarily localized in neurons and endothelial cells at early timepoints (3-6 h) after tGCI, followed by expression in microglial cells at later time-points $(72 \mathrm{hr})$ [132, 134]. Likewise, studies in focal cerebral ischemia animal models also found that NOX2 and NOX4 mRNA and protein, as well as NOX activity are elevated in the peri-infarct region of the cerebral cortex from 2-48 h after reperfusion [135-138]. Few studies have examined later time-points, but one study found NOX2 protein expression was markedly elevated in the peri-infarct region of the cortex up to 2 weeks after focal cerebral ischemia [139]. Similar to the finding in rodent models, there is also a report that NOX4 immunostaining is increased in neurons and vascular endothelial cells in the cerebral cortex of human patients after stroke, although the patient sample size in the study was very small [140]. As was the case in the tGCI model, expression of NOX2 and NOX4 was noted in multiple cell types after focal cerebral ischemia, including neurons, astrocytes and microglia. Interestingly, superoxide production and NOX2 expression was also shown to be significantly elevated in mouse cerebral arteries at $24 \mathrm{~h}$ after focal cerebral ischemia, and suggested to contribute to cerebral ischemia-induced vascular dysfunction [141]. Finally, there is a single report that NOX1 protein 
Table 2 Animal studies using genetic manipulations of NADPH oxidases on neurodegenerative disorders

\begin{tabular}{|c|c|c|c|c|}
\hline Disorder & Animal model & Genetic manipulation & Manipulation Result & References \\
\hline \multirow[t]{4}{*}{ Alzheimer's Disease } & $A \beta_{1-42}$ injection & $\mathrm{p} 47^{\text {phox }}-/-$ & $\begin{array}{l}\uparrow M 2 \text { microglial phenotype (Ym1) } \\
\downarrow M o n o c y t e \text { chemoattractant (CCL2) }\end{array}$ & {$[205]$} \\
\hline & $\operatorname{Tg} 2576$ & Nox2 -/- & $\begin{array}{l}\downarrow \text { Cerebrovascular dysfunction \& ROS } \\
\uparrow \text { Cognition }\end{array}$ & {$[407]$} \\
\hline & $\begin{array}{l}\operatorname{Tg} 2576 \\
\mathrm{~A} \beta_{1-40} \text { injection }\end{array}$ & Nox2 -/- & $\downarrow$ ROS \& vascular dysfunction & [204] \\
\hline & $\begin{array}{l}\text { APP-expressing } \\
\text { neuroblastoma }\end{array}$ & $\begin{array}{l}\text { Nox2 -/- macrophages } \\
\text { (PLB-985 X-CGD) }\end{array}$ & $\begin{array}{l}\text { Macrophages unable to kill } \\
\text { APP-expressing neuroblastoma cells }\end{array}$ & {$[408]$} \\
\hline \multirow[t]{14}{*}{ Stroke } & tMCAO & Nox1 -/- & $\uparrow$ Cortical (but not total) infarct & [59] \\
\hline & tMCAO & Nox1 -/- & $\downarrow$ Lesion, edema \& BBB disruption & [409] \\
\hline & pMCAO & Nox1 -/- & No change in infarct size & [409] \\
\hline & tMCAO & Nox1 -/- & No change in infarct size or outcome & [140] \\
\hline & tMCAO & Nox2 -/- & No change in infarct size or outcome & [140] \\
\hline & tMCAO & Nox4 -/- & $\begin{array}{l}\downarrow \text { Infarct, edema \& BBB disruption } \\
\uparrow \text { Cognition/basal motor function }\end{array}$ & [140] \\
\hline & pMCAO & Nox4 -/- & $\downarrow$ Infarct \& functional deficits & [140] \\
\hline & tMCAO & Nox2 -/- & $\downarrow$ Infarct & {$[160]$} \\
\hline & tMCAO & Nox2 -/- & $\downarrow$ Lesion \& BBB disruption & [158] \\
\hline & $\begin{array}{l}\text { Perinatal Hypoxia- } \\
\text { Ischemia (HI) }\end{array}$ & Nox2 -/- & $\begin{array}{l}\text { No change in infarct size (severe hypoxia); } \\
\uparrow \text { Infarct (moderate ischemia) }\end{array}$ & {$[410]$} \\
\hline & tMCAO & Nox2 -/- & $\begin{array}{l}\downarrow \text { Infarct \& spectrin cleavage } \\
\uparrow \text { Neurological outcome }\end{array}$ & [131] \\
\hline & tMCAO & Nox2 -/- & $\downarrow$ Infarct \& inflammation & [157] \\
\hline & $\begin{array}{l}\text { tBCCAO } \\
\text { SAH }\end{array}$ & $\begin{array}{l}\text { p4 } 47^{\text {phox }}-/- \\
\text { Nox2 -/- }\end{array}$ & $\begin{array}{l}\downarrow C A 1 \text { neuronal degeneration } \\
\text { No change in mortality, brain water } \\
\text { content, or intensity of oxidative stress }\end{array}$ & $\begin{array}{l}{[411]} \\
{[172]}\end{array}$ \\
\hline & $\mathrm{ICH}$ & Nox2 -/- & $\downarrow$ Hematoma, edema, deficits, mortality & {$[171]$} \\
\hline \multirow{2}{*}{$\begin{array}{l}\text { Traumatic } \\
\text { Brain Injury }\end{array}$} & $\mathrm{CCl}$ & Nox2 -/- & $\downarrow$ Lesion, apoptosis \& ROS & [185] \\
\hline & $\mathrm{SBl}$ & Nox2 -/- & $\uparrow$ Neurological outcome & {$[412]$} \\
\hline \multirow[t]{6}{*}{ Parkinson's Disease } & 6-OHDA & Nox2 -/- & $\begin{array}{l}\uparrow \text { Neurological outcome \& resistance } \\
\text { to neurotoxicity }\end{array}$ & {$[227]$} \\
\hline & MPTP & Nox2 -/- & Neuroprotective & {$[218]$} \\
\hline & $\mathrm{MPP}^{+}$ & Nox2 -/- neuron-glia culture & $\downarrow$ Dopaminergic neurodegeneration & [221] \\
\hline & 6-OHDA & Nox2 -/- & $\downarrow$ Rotational behavior & {$[217]$} \\
\hline & Paraquat & $\begin{array}{l}\text { NOX1 } 1-/ \text { differentiated } \\
\text { human dopaminergic cells }\end{array}$ & $\downarrow$ a-synuclein expression \& aggregation & [226] \\
\hline & Paraquat & Nox1 shRNA & $\begin{array}{l}\downarrow \text { a-synuclein expression \& aggregation, } \\
\text { ROS, dopaminergic neuronal loss }\end{array}$ & [226] \\
\hline \multirow[t]{4}{*}{$\begin{array}{l}\text { Amyotrophic Lateral } \\
\text { Sclerosis }\end{array}$} & SOD $1^{\mathrm{G} 93 \mathrm{~A}}$ & Nox2 -/- & $\begin{array}{l}\downarrow R O S \text {, protein carbonylation, neurodegeneration } \\
\uparrow \text { Longevity }\end{array}$ & {$[262]$} \\
\hline & $\mathrm{SOD} 1^{\mathrm{G} 33 \mathrm{~A}}$ & Nox1 -/- & $\begin{array}{l}\text { Delayed disease progression } \\
\uparrow \text { Survival }\end{array}$ & {$[276]$} \\
\hline & SOD $1^{G 93 A}$ & Nox2 -/- & $\begin{array}{l}\text { Delayed disease progression } \\
\downarrow \text { Muscle atrophy } \\
\uparrow \text { Survival }\end{array}$ & {$[276]$} \\
\hline & SOD1 $1^{\mathrm{G} 93 \mathrm{~A}}$ & Nox $1+/-$ or Nox $2+/-$ & $\uparrow$ Survival & {$[276]$} \\
\hline Huntington's Disease & $H D^{140 Q / 140 Q}$ & Nox2 -/- & $\begin{array}{l}\uparrow \text { Neuronal viability } \\
\downarrow R O S\end{array}$ & [246] \\
\hline Multiple Sclerosis & MOG induced EAE & $\begin{array}{l}\text { p } 47^{\text {phox }}-/- \\
\text { BV-2-myelin culture }\end{array}$ & $\downarrow R O S$, neuroinflammation & [308] \\
\hline
\end{tabular}


Table 2 Animal studies using genetic manipulations of NADPH oxidases on neurodegenerative disorders (Continued)

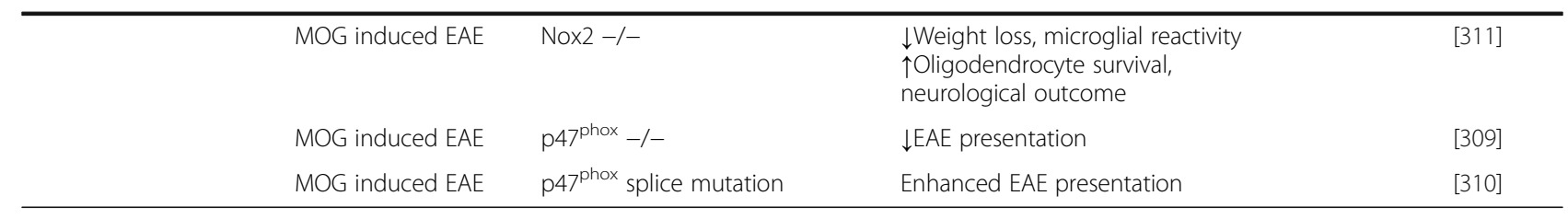

expression is significantly increased in the peri-infarct region of the cortex at $1 \mathrm{~d}, 1$ week, and 2 weeks after focal cerebral ischemia, although this remains to be confirmed [139].

An increase in NOX activation has also been reported in studies utilizing hemorrhagic models. Enhanced immunoreactivity to gp91phox associated with neuronal injury and increased gp91phox mRNA expression was reported in the rat cortex at $24 \mathrm{~h}$ after subarachnoid hemorrhage $(\mathrm{SAH})[142,143]$. Another study reported an elevation of superoxide beginning as early as $12 \mathrm{~h}$ after SAH [144]. Elevated NOX activity and superoxide production were associated with increased membrane translocation of the p47phox subunit [145] and increased membrane translocation of a NOX activator Rac [144] at $24 \mathrm{~h}$ after SAH. The activation of NOX in SAH appears to be short lived as one study found NOX activity return to baseline by $48 \mathrm{~h}$ after $\mathrm{SAH}$, with no changes in expression of gp91phox or p22phox throughout the experiment [145]. A similar acute NOX activation pattern was seen in hemorrhagic stroke where NOX2 protein levels were shown to be increased in the striatum at $12 \mathrm{~h}$, and peaking at $24 \mathrm{~h}$ after intracerebral hemorrhage (ICH) [146]. Gp91phox was primarily expressed in activated microglia and colocalized with peroxynitrite at $24 \mathrm{~h}$ after $\mathrm{ICH}$ in the injured hemisphere [147]. Human data for NOX activation in hemorrhagic stroke models are scarce, but a study of the Chinese Han population resulted in the identification of a p22phox polymorphism associated with increased NOX activation and susceptibility to ICH [148]. While clearly more studies using different injury models are needed to solidify the evidence for NOX involvement in the pathogenesis of hemorrhagic stroke, the current findings suggests that NOX activation is involved in the acute phase of hemorrhagic stroke, as opposed to a more prolonged involvement in ischemic stroke.

Neuroprotective effect of NOX inhibition in stroke In agreement with the induction of NOX isoforms and elevated NADPH oxidase activity after cerebral ischemia, NOX inhibitor and knockout studies support a critical role for NADPH oxidase in ROS generation, oxidative stress damage, inflammation, and functional outcome following cerebral ischemia (Table 2). For instance, a NOX2 selective inhibitor, gp91ds-tat, but not a scrambled control peptide, was shown to significantly attenuate the increase in NADPH oxidase activity and superoxide level in the hippocampal CA1 region after tGCI, and was strongly neuroprotective when administered 30 mins before induction of GCI [132]. Further work showed that gp91ds-tat reduced acetylation and activation of p53 and reduced expression of the apoptotic factor, puma in the rat hippocampus after tGCI [149]. Many cerebral ischemia studies have used apocynin, a non-isoform-specific NOX inhibitor. It should be noted that apocynin has also been reported to have direct anti-ROS scavenging ability [150]. Nevertheless, apocynin has been shown to reduce superoxide elevation, oxidative stress, post-ischemic inflammation, and infarct volume, and improve neurological function in focal cerebral ischemia animal models [131, 151-156]. These studies used a dose range from $2.5-50 \mathrm{mg} / \mathrm{kg}$ and either an intravenous or intraperitoneal administration route in mice and rats. Apocynin treatment was initiated at various times ranging from $-60 \mathrm{~min}$ to +120 min relative to the initiation of stroke. This indicates that apocynin can be protective at least out to $2 \mathrm{~h}$ after the onset of stroke, although it should be pointed out that some dissenting studies failed to find post-stroke protection with apocynin [140, 151], possibly due to missing a time window of therapeutic apocynin application or the narrow therapeutic dose range of apocynin [155]. Interestingly, the ability of apocynin to reduce infarct size after focal cerebral ischemia is lost in NOX2 knockout mice, suggesting its effects require NOX2 [151].

Knockout animal studies have further implicated NOX2 and NOX4 as the principal NOX isoforms involved in mediating oxidative stress and brain injury following cerebral ischemia (Table 2). For instance, a majority of studies have reported that NOX2 knockout animals have significantly reduced infarct size following focal cerebral ischemia [131, 153, 157-160], although there are a few dissenting studies [140, 161]. NOX2 knockout animals also have been demonstrated to have reduced ROS and oxidative stress in the brain after focal cerebral ischemia [131, 159], as well as reduced blood brain barrier disruption [158], and significantly attenuated post-ischemic inflammation [131, 157].

Mechanistically, studies have shown that glutamate excitotoxicity plays an important role in brain damage following cerebral ischemia [162-164]. Recent work suggests a role for NOX2 in regulating post-stroke glutamate excitotoxicity. For instance, NOX2 has been demonstrated 
to mediate expression of complexin II, which via SNARE signaling induces glutamate excitotoxicity [165]. Similarly, NOX activation appears necessary for the NMDA path of excitotoxicity. The active transmembrane complex composed of p40phox, p22phox, and gp91phox produces superoxide extracellularly and $\mathrm{H}^{+}$intracellularly, where a $\mathrm{Na}^{+} / \mathrm{H}^{+}$exchanger removes intracellular $\mathrm{H}^{+}$to maintain NOX activity. When the $\mathrm{Na}^{+} / \mathrm{H}^{+}$exchanger is inhibited, NOX activity appears to decrease as shown by decreased superoxide production and attenuated excitotoxicity [84]. These results highlight the role of NADPH oxidase in mediating NMDA excitotoxicity.

Furthermore, there is evidence that NADPH oxidase is critical for the release of neurotoxic factors from activated microglia after ischemia. For instance, chemical ischemia has been shown to induce NOX2 elevation and ROS generation in cultured BV2 microglia cells, and conditioned media from the activated microglia induces robust neuronal cell death in vitro [166]. Moreover, NOX2 siRNA knockdown or treatment with the NOX inhibitor, apocynin blocked the cell death-inducing effect of the activated microglia-conditioned media [166]. An important question is what is the contribution of NOX activation in resident microglia in the brain versus NOX activation in circulating immune cells. Tang et. al. attempted to address this question by performing bone marrow chimera studies using wild-type and NOX2-KO mice [153]. The study revealed that wild-type mice receiving NOX2-KO bone marrow had smaller infarct sizes and less hemorrhage than NOX2 KO mice receiving wild-type bone marrow. The authors concluded that while NOX2 from both resident brain cells and circulating immune cells contributed to ischemic brain injury and hemorrhage, based on the bone marrow chimera results, NOX2 from the circulating cells might contribute more to exacerbation of brain ischemia than brain resident cells.

Finally, in addition to the role for NOX2 in mediating cerebral ischemia brain damage, there is one report that showed NOX4 knockout mice have reduced oxidative stress and neurodegeneration following focal cerebral ischemia [140]. Likewise, administration of the NOX inhibitor VAS2870 at 2 and $12 \mathrm{~h}$ after tMCAO also reduces ischemic brain injury after focal cerebral ischemia, an effect possibly due to inhibition of NOX4 [140]. Moreover, mice engineered to overexpress NOX4 in brain pericytes had significantly greater infarct volume after focal cerebral ischemia, along with enhanced reactive oxygen species production and blood-brain barrier breakdown in the peri-infarct region [167]. VAS2870 IV treatment in a tMCAO model showed increased expression of microRNAs targeting NOX2 and NOX4, suggesting that the neuroprotective effects of VAS2870 may also be mediated through regulation of microRNAs
[168]. Taken together, the above studies indicate that NOX2 and NOX4 play an important role in infarct damage, inflammation and neurological deficits that occur following cerebral ischemia.

The evidence of NOX inhibition in hemorrhagic stroke is more limited. A study of SAH using diphenyleneiodonium chloride (DPI) to inhibit NOX ameliorated the decreased MCA luminal diameter seen after SAH [145], indicating a potential for NOX inhibition to reduce cerebral vasospasms that may complicate SAH. In studies investigating hemorrhagic transformation after ischemic stroke, NOX inhibition via VAS2870 was able to reduce infarct volume and attenuate NOX2 and NOX4 expression in rats, which correlated with better outcome and reduced hemorrhagic transformation after reperfusion in acute ischemic stroke [169]. Another study found that apocynin treatment at high doses did not improve outcome in a collagenase model of rat ICH [170], although the narrow neuroprotective dose range of apocynin may account for the lack of neuroprotection seen at high doses [155]. Modulation of NOX expression or activity has also been implicated in the protective effects of hyperbaric oxygen in SAH [142, 143], Rac inhibition in SAH [144], adiponectin paralog in ICH [146], and Brilliant Blue $\mathrm{G}$ in $\mathrm{ICH}$ [147]. As these treatments are not specific in targeting NOX, the value of NOX as a therapeutic target in hemorrhagic stroke remains to be validated with more studies utilizing NOX-specific inhibitors. A few knockout studies have been done in investigating the role of NOX enzymes in hemorrhagic stroke. Gp91phox KO mice show decreased oxidative products, reduced brain edema, smaller hematoma size, decreased neurological deficits, and decreased mortality as opposed to wild type mice after collagenase induced ICH [171]. However, an endovascular perforation model of SAH with gp91phox $\mathrm{KO}$ mice showed no difference in the cerebral blood flow, brain edema, intensity of oxidative stress, or mortality between WT and $\mathrm{KO}$ mice [172]. It is uncertain whether different disease models or the acute window of NOX activation in hemorrhagic stoke may account for the variability in reported data. These preliminary studies with NOX KO mice in hemorrhagic stroke require further validation.

\section{Traumatic brain injury}

NOX activation in traumatic train injury In addition to a role in stroke, there is growing evidence that NOX activation contributes significantly to the neuropathology of traumatic brain injury (TBI). TBI has a nearly $40 \%$ mortality rate [173] and is the leading cause of death in young people, especially with increasing rates of motor vehicle accidents [174]. In recent years, TBI has gained recognition as a chronic and progressive disorder resulting from an acute trauma [175]. The primary 
mechanical injury over time leads to development of the secondary injury such as edema, ischemia, hypoxia, neuroinflammation, and neurodegeneration of the cortex and underlying hippocampus [176-178]. Oxidative stress is thought to play a key role in the development of cerebral edema, breakdown of the blood brain barrier (BBB), and the secondary neuronal damage found post-TBI. The initial focal injury spreads via inflammatory signals to previously healthy regions nearby and amplifies the original tissue injury [179, 180]. BBB disruptions allow increased permeability that contribute to the cerebral edema following TBI [181-183].

Since oxidative stress plays a key role in TBI, several groups have examined the role of NOX isoforms, particularly NOX2 activation in TBI pathology. Studies from our group and others showed that NOX2 expression and NADPH oxidase activity increases rapidly in the mouse cerebral cortex and hippocampal CA1 region in an animal model of TBI (controlled cortical impact), with an early peak at $1 \mathrm{~h}$, followed by a secondary peak from 24-96 h after TBI $[133,184]$. The first early peak of NADPH oxidase activity was in neurons, while the later second peak primarily occurred in microglia [133, 184, 185]. Further work showed that NOX2 expression remained elevated above sham controls at 7 days and 28 days post-TBI in rats [71]. At these later stages, pro-inflammatory M1 microglia were reported to have high NOX2 expression after TBI in a controlled cortical impact model in mice [186]. In fact, NOX2 may contribute to persistent microglia activation that has been observed in the cortex chronically after TBI, as NOX2 was found to be expressed in highly activated microglia at the margins of the expanding lesion at 1-year after the TBI [175]. NOX4 has also been reported to be elevated in the cortex after controlled cortical impact or repeated blast injury in rats $[71,187]$. NOX3 was shown to be present in neurons constitutively in both injured and uninjured animals, and its role in TBI remains unclear [71]. Other NOX isoforms have not been investigated in the context of TBI.

Similar to the results obtained in animal studies described above, immunofluorescent staining of human post-mortem TBI brain samples showed that NOX2 and NOX4 expression was increased in the cortex at 6-24 and 24-48 h after TBI, respectively, and abnormal NOX2 and NOX4 expression showed correlation to patient prognosis [188]. NOX4 expression has also been reported to be increased in postmortem brain samples from athletes diagnosed with chronic traumatic encephalopathy, and the increase in NOX4 activity correlated with increased superoxide formation [187]. Increased ROS production and elevated expression of NOX2 has also been reported in circulating neutrophils after TBI in humans, which paralleled a significant increase in plasma levels of inflammatory cytokines [189]. These findings suggest an increased systemic inflammatory response occurs after TBI, which may involve facilitation by NOX2. The systemic inflammatory response after TBI could cause increased local secondary damage in the brain, as well as systemic damage to bystander peripheral tissues. Targeting NOX inhibition in these systemic neutrophils could potentially protect uninjured organs from secondary damage following TBI.

Neuroprotective effect of NOX inhibition in traumatic brain injury To examine a potential causative role of NADPH oxidase in TBI pathology and outcome, investigators have used NADPH oxidase inhibitors and NOX2 knockout animals. Administration of the NADPH oxidase inhibitor, apocynin markedly inhibited proinflammatory microglial activation and oxidative stress damage to neurons $[71,133,184,190]$, as well as attenuated TBI-induction of AD-related proteins and axonal damage markers, such as $\beta$-amyloid and amyloid precursor protein [133]. Furthermore administration of apocynin or the more specific NOX2 inhibitor, gp91ds-tat, induced significant neuroprotection against TBI and reduced neurological deficits [133, 184, 191]. Administration of gp91ds-tat also altered microglia polarization after TBI to favor the M2-like anti-inflammatory phenotype [186], suggesting an important role of NADPH oxidase in promoting the "pro-inflammatory" M1-like microglia phenotype after TBI. Similarly, NOX2 knockout mice have decreased contusion size, as well as decreased superoxide and peroxynitrite metabolism, and a decreased number of apoptotic cells in the cortex after TBI, confirming a possible role for NOX2 in TBI pathology [185] (Table 2). While NOX4 has been reported to be elevated after TBI (like NOX2) [71, 187, 188], there have been as yet no comparable studies examining TBI pathology or outcome in NOX4 knockout mice. Thus, studies to address this deficit are needed.

\section{Alzheimer's disease \\ NOX activation in Alzheimer's disease Alzheimer's} disease $(\mathrm{AD})$ is characterized by progressive memory loss, cognitive and executive impairment, with varying degrees of aphasia, apraxia, and agnosia [98, 192]. Early in $\mathrm{AD}$ progression, cognitive symptoms are caused by damage to the hippocampus [193, 194]. Oxidative stress, particularly that created by NOX2 induction, has been implicated to have a significant role in the development of $\mathrm{AD}[24,195,196]$. Postmortem analyses of cerebral cortices of human AD patients showed increased p47phox and p67phox expression and translocation to the membrane in AD brains [196], suggesting that NOX is activated in $\mathrm{AD}$. Antemortem behavioral testing and postmortem histopathological assessment (of frontal and 
temporal cortex) in patients with either no cognitive impairment, preclinical AD, mild cognitive impairment, early $\mathrm{AD}$, or mild-to-moderate $\mathrm{AD}$, confirmed elevation of p47phox, p67phox, p40phox and p22phox, as well as elevation of NOX activity in mild cognitive impairment and AD patients [197]. There was also a robust correlation between NOX activity and an individual's cognitive status (e.g. as NOX enzyme activity increased, cognitive performance decreased). The enhanced induction of NOX isoforms and activity in $\mathrm{AD}$, may be due, in part, to elevated $\beta$-amyloid $(A \beta)$ levels, as treatment of microglia with $A \beta$ has been shown to induce $p 47$ phox and p67phox subunit translocation to the cell membrane, indicating an activation of microglial NOX and ROS generation [196]. Furthermore, increased expression of NOX2 and oxidative stress has been reported in activated microglia surrounding $A \beta$-laden capillaries from patients with cerebral amyloid angiopathy $[198,199]$.

In addition to elevation of NOX2, there is evidence that NOX4 expression is significantly increased in the brain of aged humanized APPxPS1 knock-in mice, and that there is a significant linear correlation between NOX activity and age-dependent increases of A $\beta$ (1-42) and cognitive dysfunction [200]. Another study showed that NOX1 and NOX3 mRNA levels are increased in the brain during early stages of AD [201]. Interestingly, NOX1 mRNA levels were also reported to be significantly elevated in the hippocampal CA1 region in a bilateral cerebral artery occlusion (BCCAO) rodent model of vascular dementia, and the effect correlated with increased superoxide and ROS levels [202]. As a whole, these studies provide correlational evidence of increased $\mathrm{NADPH}$ oxidase subunit expression and NADPH oxidase activity in the brain in $\mathrm{AD}$, which could contribute to $\mathrm{AD}$ pathology. Below we discuss evidence from inhibitor and knockout/knockdown studies that support a role for NADPH oxidase in AD pathology and progression.

Neuroprotective effect of NOX inhibition in Alzheimer's disease In support of NOX2 elevation having an important pathological role in $\mathrm{AD}$, treatment with the $\mathrm{NADPH}$ oxidase inhibitor, apocynin markedly reduced oxidative stress, cerebral amyloid angiopathy, and cerebral amyloid angiopathy-induced vasomotor impairment in an animal model of AD (aged APP-overexpressing Tg2576 mice) [203]. As shown in Table 2, other studies showed that NOX2 inactivation by use of NOX2 knockout mice crossed with $\mathrm{Tg} 2576$ mice or use of the specific NOX2 inhibitor, gp91ds-tat also significantly reduced oxidative stress, improved the neurovascular dysfunction, and ameliorated behavioral deficits in aged Tg2576 mice [204]. Surprisingly, the beneficial effect of NOX2 inactivation in aged TG2576 mice occurred without reductions in brain amyloid-beta peptide levels or amyloid plaques. However, treatment with the NOX2 inhibitor, gp91ds-tat or knockout of NOX2 has been shown to significantly attenuate the ability of $A \beta$ to induce ROS in the brain [204], suggesting that NOX2 is a major source of ROS induced by $A \beta$. Furthermore, examination of human AD postmortem brain samples found that microglia "proinflammatory" (M1) marker gene expression is increased, while expression of the anti-inflammatory (M2) marker genes were decreased, as compared to agematched controls [205]. This effect was correlated with an increase of the NOX 2 p47phox subunit in the AD brain, and further studies revealed that p47phox $\mathrm{KO}$ mice and apocynin-treated mice showed a switch from "proinflammatory" M1 to the "anti-inflammatory" M2 microglia phenotype following induction of neuroinflammation [205]. These results suggest that NADPH oxidase may facilitate induction of the proinflammatory M1 microglia phenotype during neuroinflammation and AD. Finally, while NOX1, NOX3 and NOX4 have been reported to be elevated in $\mathrm{AD}$, their precise role and contribution to $\mathrm{AD}$ is currently unclear. Therefore, more studies are needed to assess the potential role of these NOX isoforms in AD.

\section{Parkinson's disease}

NOX activation in Parkinson's disease Parkinson's disease (PD) is the second most common neurodegenerative disorder following $\mathrm{AD}$, with progressive symptoms such as resting tremor, rigidity, akinesia, and stooped posture caused by a characteristic loss of dopaminergic neurons in the substantia nigra pars compacta [206-208]. Models of PD often use the neurotoxins, 6-hydroxydopamine (6-OHDA), paraquat, 1-methyl-4-phenyl-1,2,3,6-tetrahydropyridine (MPTP) and rotenone, all of which kill dopaminergic neurons via mechanisms that seem to converge on oxidative stress [209]. Human PD brains have shown evidence of oxidative damage in degenerating areas such as the substantia nigra [210]. Post-mortem analysis and animal studies suggest a role of inflammation in PD pathology [211, 212], as evidenced by increased glial activation [213], which appears to be a persistent chronic activation [214]. Microglia have been suggested to contribute to the damage of dopaminergic neurons in PD via NOX-derived ROS [215]. In support of this contention, NOX1 expression has been reported to increase after striatal injection of 6-OHDA and is associated with a simultaneous increase in DNA oxidative stress [216]. Additionally, following 6-OHDA induction, there is an increase in NOX1 and NOX2 gene expression in the mouse striatum, and NOX2 expression in the substantia nigra [217]. In vivo and in vitro studies of PD induced by paraquat have shown increased expression of NOX1 and synucleins [217]. NOX2 expression has also been shown to increase in mouse brains after 
administration of MPTP [218] and to be elevated in PD human brains [218]. Likewise, NOX2 and NADPH oxidase activity have been reported to be increased in the substantia nigra in an LPS-induced animal model of PD [219]. These findings demonstrate an elevation of NOX1 and NOX2 may contribute to the dopaminergic neuronal loss that occurs in PD. The mechanisms that lead to NOX induction in PD are unclear; however, $\alpha$-synuclein, a key protein implicated in PD pathology, has been shown to activate NOX2 in microglia via a process that is mediated by the purinergic P2X7 receptor [220]. Likewise, substance $\mathrm{P}$, which is dysregulated and suggested to contribute to PD pathogenesis, has also been shown to activate NOX2 in microglia, an effect critical for substance P-induced dopaminergic neurotoxicity [221]. Other PD-related genes have been reported to affect NOX activation. DJ-1/Park7 can bind to p47phox to alter NOX activation [222, 223], and silencing of DJ-1 has been shown to increase NOX4 expression and ROS production [224]. In addition, NOX has been implicated as a potential mechanism underlying neuronal vulnerability associated with PINK1 dysfunction [225]. While interesting, further studies are needed using PD models in order to elicit whether these PD-related genes have a functional role in mediating downstream NOX activation.

Neuroprotective effect of NOX inhibition in Parkinson's disease In support of a role of NOX1 in the pathology of Parkinson's disease, NOX1 KO mice have a significant attenuation of DNA oxidative stress in a 6-OHDA striatal injection PD model (Table 2) [216]. Furthermore, in both in vitro and in vivo paraquat-induced PD models, NOX1 knockdown significantly reduced $\alpha$-synuclein expression and aggregation, as well as oxidative stress and dopaminergic neuronal cell loss [226]. With respect to NOX2, NOX2 KO mice exhibited less dopaminergic neuronal degeneration than their controls when lesioned by 6-OHDA [227]. Likewise, dopaminergic neurons from NOX2 $\mathrm{KO}$ mice were significantly more resistant to rotenone neurotoxicity (an environmental toxin linked to PD) than those from wild-type mice [228]. The enhanced neurotoxicity of rotenone was suggested to be due to release of NOX2derived superoxide from activated microglia. This suggestion was supported by the fact that addition of microglia prepared from wild-type mice, but not from NOX2 KO mice, to neuron-enriched cultures markedly increased rotenone-induced degeneration of dopaminergic neurons [228]. Further evidence of a role of NOX2 in PD pathogenesis has come from NOX inhibitor studies. For instance, in a leucine-rich repeat kinase 2 transgenic PD mouse model, treatment with diapocynin, an orally active apocynin derivative, relieved early PD symptoms regarding coordination and balance [229]. Oral diapocynin treatment also exerted anti-inflammatory and neuroprotective effects in a MPTP mouse model of $\mathrm{PD}$, where it preserved locomotor function and halted disease progression in a chronic mouse model of PD [230]. Furthermore, oral apocynin administration in a MPPT monkey model of PD increased the number of surviving dopaminergic neurons and relieved PD symptoms and motor function deterioration [231]. Taken together, these studies implicate a role for NOX1 and NOX2 in PD pathogenesis and targeting them may have therapeutic efficacy and should be explored further.

\section{Huntington's disease}

NOX activation in Huntington's disease Huntington's disease (HD) is a relentlessly progressive and fatal neurodegenerative disorder involving an autosomal-dominant inheritance of trinucleotide (CAG) repeat expansion in the huntingtin gene, which clinically manifests in choreiform movements, psychiatric disturbances, and cognitive impairments [232-236]. HD shows selectivity for atrophy and loss of medium spiny neurons in the striatum, but eventually can lead to atrophy of the cerebral cortex at later stages of the disease [233, 235]. Though not necessarily a direct effect of the mutant huntingtin, oxidative stress has been implicated as an important mechanism of HD pathology as susceptible neurons may have impaired tolerance of ROS [234, 237, 238]. Studies of human HD brain and tissue samples found increased oxidative damage in the caudate [239], parietal cortex [240], and peripheral blood $[241,242]$ (as measured by 8-hydroxy2'-deoxyguanosine), in CSF (as measured by isoprostanes) [243], and in serum (as measured by malondialdehyde and 4-hydroxynonenal) [71] indicating a role of oxidative stress in HD pathology. Furthermore, reduced SOD antioxidant activity in the cortex and cerebellum [239] and in erythrocytes [241] also support an impaired antioxidant capacity in HD patients. However, the evidence surrounding the presence of oxidative damage markers in post-mortem brain tissue is not uniform since a report exists showing unaltered levels of oxidative DNA damage, protein carbonylation, and lipid peroxidation in HD brain samples when compared to controls [138]. Nonetheless, animal studies using transgenic models of HD have provided a stronger consensus in the role of ROS in HD pathology. In HD transgenic R6/2 mice that develop a movement disorder similar to HD presentation at 14-16 weeks, the forebrain showed increased signs of DNA oxidation at 12-14 weeks of age [244]. Despite initial increases in SOD function after disease onset, older mice (35 weeks) show diminished protection by SOD [245]. Regarding potential NOX involvement in HD, human HD patient brain lysates showed increased NOX activity in the cortex and striatum [246]. Furthermore, studies using a rat model of intrastriatal quinolinic acid 
injection for HD showed increased NOX-linked striatal superoxide production that increased with the addition of NOX substrate, NADH [247]. A model utilizing 3nitroproprionic acid-induced striatal lesions, which mimics many characteristics of HD [3], likewise found increased hydroxyl free radicals in the lesioned striatum [248]. Furthermore, studies using a mouse model of HD found that NOX activity was significantly elevated in cortical and striatal synaptosomes in $\mathrm{HD}^{140 \mathrm{Q} / 140 \mathrm{Q}}$ mice [246], and in primary neurons derived from $\mathrm{HD}^{140 \mathrm{Q} / 140 \mathrm{Q}}$ mice [246]. A PC12 cell line in vitro study of CAG repeatexpanded proteins also showed increased oxidative damage attributable to NOX [14]. The emerging evidence suggests a role for NOX2 in generating oxidative stress in HD pathology; however, cell type- and isoformspecific effects remains unexplored, and thus additional studies are needed to address this issue.

Neuroprotective effect of NOX inhibition in Huntington's disease Despite the recent exploration of the role of NOX enzymes in the pathogenesis of HD, there is evidence supporting that inhibition of NOX may be beneficial. In a rat intrastriatal quinolinic acid injection model of HD, both pre- and post-lesion apocynin treatment decreased superoxide levels and attenuated behavioral alterations seen in untreated, lesioned animals [247]. Furthermore, both apocynin and DPI were able to suppress superoxide generation after striatal lesion in the presence of NOX substrate, NADH [247]. This supports that NOX is actively participating in the pathology of this model of HD. Apocynin and DPI treatment of primary cortical and striatal neurons derived from $\mathrm{HD}^{140 \mathrm{Q} / 140 \mathrm{Q}}$ transgenic mice reduced NOX enzyme activity to the levels of WT neurons [246], as well as reduced ROS generation, increased viability, and improved morphology of the neurons [246]. These $\mathrm{HD}^{140 \mathrm{Q} / 140 \mathrm{Q}}$ derived neurons also showed increased neuronal viability when treated either with a superoxide quencher, EUK189, or a more selective NOX inhibitor, VAS2870 [246]. Though VAS2870 has been reported as a selective NOX2 inhibitor, other studies have revealed its effect on other NOX isoforms and cannot be used to implicate NOX2 as the key NOX isoform in HD pathology. However, NOX2 involvement can be studied using gp91ds-tat, a more selective inhibitor of NOX2 [249]. In the $\mathrm{PC} 12$ cell line, treatment with gp91ds-tat reduced ROS levels, dissolved nuclear aggregates induced by expanded polyglutamine peptides, and prevented the formation of new aggregates [14], suggesting that NOX inhibition may be beneficial. Though investigations on the role of NOX2 in HD is a recent endeavor, results so far seem to suggest a key role of NOX2 involvement in HD pathology. In support of this possibility, cortical neurons derived from NOX2-deleted $\mathrm{HD}^{140 \mathrm{Q} / 140 \mathrm{Q}}$ mice showed reduced
NOX activity and increased cell survival as compared to NOX2-WT HD ${ }^{140 Q / 140 Q}$ mice [246]. These results suggest that NOX2 inhibition can be neuroprotective, and that further studies utilizing NOX2 $\mathrm{KO}$ mice in HD models are needed to further confirm the role of NOX2, as well as the potential benefits of NOX inhibition on behavioral parameters, cognitive health, and disease outcome. In addition, additional studies testing the role of other NOX isoforms in HD pathology are also needed.

\section{Amyotrophic lateral sclerosis}

NOX activation in amyotrophic lateral sclerosis Amyotrophic lateral sclerosis (ALS) is characterized by progressive motor neuron degeneration and subsequent gliosis that burdens patients with muscle weakness and disability, eventually leading to fatal respiratory and cardiac deficits within 3-5 years of diagnosis [250, 251]. Despite over 30 years of research using animal models, only a single drug has been approved for the treatment of ALS (riluzole), and its effect on survival is modest [252]. Although the exact mechanism of motor neuron death in ALS is still under investigation, oxidative stress has been implicated in the disease progression [253, 254]. Patients suffering from either sporadic or familial ALS showed increased oxidative stress markers such as protein carbonylation [255], nitration of protein-tyrosine residues [256], lipid peroxidation [257], protein glycoxidation [257], and mRNA oxidation [258] in their spinal cords. Furthermore, similar increases in oxidative stress markers have also been detected in the brain [259] and CSF [260] of ALS patients. Despite an account where nitrotyrosine was not found to be significantly elevated in the CSF of ALS patients [261], there appears to be a consensus that oxidative stress plays a role in ALS pathology. In particular, post-mortem spinal cord samples from patients with sporadic ALS showed a 3-fold increase in NOX2 expression and increased protein carbonyl adducts than in control post-mortem samples [262]. An animal model commonly used to study ALS is the overexpression of mutant superoxide dismutase one (SOD1), since dominant mutations in SOD1 lead to familial ALS in humans [263]. SOD1 overexpression likely leads to motor neuron damage due to the increase in oxidative stress, in part due to NOX activation. In the most widely used mouse model of ALS (SOD1G93A), NOX2 is upregulated in the ALS mice [262]. Furthermore, ALS mice overexpressing SOD1 had enhanced NOX-dependent superoxide production in the brain and spinal cord [264]. Rac1, an important regulator of NOX, was reported to directly interact with SOD1 [264]. Altered Rac1 modulation by mutant SOD1 (SOD1L8Q) has been implicated in the persistence of NOX dependent superoxide production [264], and binding of mutant SOD1 to Rac1 has been suggested to amplify microglial NOX2 production of ROS [265]. 
Likewise, human astrocytes that overexpress mutated SOD1 (SOD1G37R) up-regulate NOX2 [266]. In addition to evidence of NOX2 elevation in ALS, human whole genome analysis of sporadic ALS patients linked NOX4 to have a possible role in ALS disease progression [267].

Neuroprotective effect of NOX inhibition in amyotrophic lateral sclerosis Since oxidative stress is implicated in the pathogenesis of ALS, antioxidants have been evaluated for their efficacy to limit disease progression. However, clinical trials based on antioxidants in ALS have been unsuccessful. For instance, Vitamin E [268-270], coenzyme Q10 [271, 272], and edaravone [273], despite slowing motor neuron degeneration in mice SOD1G93A model [274], are a few tested antioxidants and free radical scavengers that have shown no major improvements or limited improvement in quality of life in ALS clinical trials. The lack of translational efficacy may be partially due to pharmacological inability to cross the BBB, variability in experimental conditions, or generalized drug mechanisms that overlook the value of targeting a specific oxidative pathway. Based on the potential role of NOX enzymes in ALS pathology, it is reasonable to investigate whether targeting of NOX can be therapeutic. Studies investigating NOX's role in human ALS patients found that patients that had lower NOX2 activity in their peripheral blood cells showed significant increases in survival [275]. Additionally, ALS mice deficient in NOX2 showed decreased oxidative stress in spinal cords and a modest increase in lifespan (Table 2) [262]. Likewise, ALS mice having either deletion of NOX1 or NOX2 showed increased survival and delayed disease onset, and these effects are greater in the NOX2 deleted ALS mice [276]. Interestingly, female ALS mice heterozygous for either NOX1 or NOX2 also showed significantly increased survival [276]. Apocynin treatment was also shown to improve motor neuron survival when co-cultured with astrocytes carrying a mutant SOD1 (G37R) [266], further supporting that NOX inhibition can have a neuroprotective role in ALS. Pharmacological inhibition of NOX has also shown benefits in animal models of ALS. For example, long-term treatment with apocynin beginning at an early age ( 2 weeks) prolonged survival by nearly $50 \%$ and increased the number of motor neurons in the spinal cord in hemizygous SOD $1^{\mathrm{G} 93 \mathrm{~A}}$ mice [264], showing that NOX inhibition can delay ALS progression. Apocynin treatment initiated at a later age (80 days) also showed decreased disease progression, although the effect was minor [264]. In contrast to the above study, another study reported little beneficial effect of apocynin or diapocynin on extending the lifespan in the SOD1G93A model [277]. Clearly, further studies are needed to clarify the role of NOX isoforms in ALS. Use of inducible and cell- specific NOX subunit $\mathrm{KO}$ models may also add further clarification and avoid confounds of global KO models.

\section{Multiple sclerosis}

NOX activation in multiple sclerosis Multiple Sclerosis (MS) is a chronic CNS disease of autoimmune origin that leads to demyelination, impaired motor function, and neurodegeneration [7, 278-282]. Inflammation and neurodegeneration are some of the key characteristics of MS [7, 282, 283]. Accumulating evidence suggests that oxidative stress plays a key role in MS pathology [281, 284-287]. Brain samples from human patients affected with MS show increased signs of oxidative damage to DNA, proteins, and lipids within and outside of MS plaques in the brain [288-294]. It has been suggested that NOX in activated microglia contributes to the production detrimental ROS and plays an important role in MS pathogenesis [295]. NOX2, NOX1, and NOXO1 were shown to be upregulated in activated microglia found in active demyelinating and chronic MS lesions sampled from human MS patient brain tissue [296]. Furthermore, NOX2 was also upregulated in activated microglia in pre-active MS lesions found throughout normal appearing white matter of MS patients [297], suggesting a role of activated microglia in the production of ROS in MS. However, a protective role of ROS has been suggested as decreased ROS production by isolated peripheral blood leukocytes from MS patients were associated with a more severe MS presentation [298]. This suggests that the role of microglia and NOX-mediated ROS production may be more complicated and would need further animal model studies to elucidate the role of NOX in MS pathology. In animal studies, experimental autoimmune encephalomyelitis (EAE) is the most commonly used model to simulate pathological and clinical findings of MS [299]. However, it has been reported that notable differences in observed tissue injury and oxidative stress exist between human MS and animal EAE models where EAE models potentially underrepresent the extent of injury found in human MS studies [300]. Thus, the NOX activation seen in the EAE studies may actually be greater in the human MS model. In vitro, NOX has been shown to increase BBB permeability of brain endothelial cells in EAE [301]. In EAE induced mice, the brain and spinal cord exhibit increased NOX enzyme activity and NOX expression as compared to that of control mice [302, 303], suggesting that NOX activity may contribute to tissue damage in the course of EAE. In particular, NOX2 and the subunits p67, p47, p40, and p22phox mRNA showed increase in both relapsing-remitting and chronic models of EAE [304], indicating a probably increase in oxidative stress during the peak stages of EAE and in the later progressive stage of EAE. In a different study, NOX2 expression was also seen to be elevated in microglia during 
remission phases of relapsing-remitting EAE [305], which coincided with observed impairments in hippocampal CA1 synaptic plasticity [305]. Despite possible differences between EAE and MS, animal models of EAE have furthered our knowledge on the role of NOX in disease progression.

\section{Neuroprotective effect of NOX inhibition in multiple} sclerosis The use of EAE animal models in conjunction with NOX inhibition techniques show a more causative role of NOX that may be contributing to MS pathology. In EAE in vitro studies, NOX inhibition with apocynin was able to reduce BBB permeability seen in EAE [301, 306]. Early studies have shown that blocking NOX via apocynin or DPI reduces ROS formation and prevents phagocytosis of myelin [307]. Similar results were obtained by either blocking NOX assembly or by deletion of $\mathrm{p} 47$ phox, where ROS production and neuroinflammation were both attenuated in a model of isolated myelin and primary microglial culture [308]. Studies of the p47phox subunit report a complex function. Mice with $\mathrm{p} 47$ phox deletion develop decreased EAE, showing no obvious signs of EAE as compared to WT mice who developed modest of severe disease after EAE induction [309]. However, mutant mice with truncated or nonfunctional $\mathrm{p} 47$ phox proteins showed enhanced disease progression after EAE induction [310], indicating that the oxidative burst of NOX enzymes may serve a beneficial role in modulating disease progression. Nonetheless, more studies have reported benefits of NOX inhibition. Isolated microglia from NOX2 $\mathrm{KO}$ mice showed reduced toxicity to oligodendrocytes [295]. Inhibition with DPI also prevented activated microglia from killing oligodendrocytes [295]. In vivo, NOX2 deletion in mouse models of EAE prevented the weight loss, attenuated oligodendrocyte loss, and reduced microglia reactivity that were all observed in WT EAE mice [311]. Deletion of NOX2 also improved neurological outcome in EAE mice [311], showing that these NOX2 $\mathrm{KO}$ mice are more resistant to EAE. Mice treated with apocynin to inhibit NOX also showed reduced clinical symptoms of EAE, reduced demyelination, and reduced infiltration of immune cells [306]. It has also been shown that apocynin can reduce synaptic plasticity in the hippocampal CA1 region during a remission phase of EAE [305]. The evidence based on genetic studies of NOX deletion and inhibition demonstrates that modulation of NOX can therapeutically inhibit some clinical features and neuropathological changes associated with EAE, and ultimately MS.

\section{Translational relevance - NOX inhibitors as potential} therapeutic agents

Although there is much promise in using a NOX inhibitor for the management of brain injury and neurodegenerative disorders, preclinical studies have been limited due to many factors. To date, preclinical ROS scavenging trials lack consistency in demonstrating their beneficial effects [312] despite showing promise in animal studies. The lack of translational success could possibly be due to issues with targeting within the therapeutic window, animal model adequacy, the sample size, and bioavailability [313]. The evidence discussed above supporting a role of NOX in brain injury and neurodegeneration has provided impetus towards examining the therapeutic efficacy of NOX inhibitors in these disorders [73], as this approach may offer the best therapeutic option for treating disorders associated with oxidative stress [314]. One challenge that NOX inhibitors must overcome for successful translation to the clinic is the timing of application. Most inhibition studies referenced in the above sections have been initiated before injury or during the acute phase of the disease immediately following injury. Not enough studies have been done in exploring whether delayed inhibition of NOX at later time points following injury may offer different therapeutic effects, especially in disease models where NOX activation post-injury is prolonged. Since NOX inhibition at later time points are more relevant to a clinical setting, more exploration in the early versus late inhibition can increase the success of translating NOX inhibitors to clinical models. Challenges also exist in determining the optimal treatment window for chronic neurodegenerative disorders that progress over many years, where no single injury, such as in stroke or TBI, is the root of disease. In chronic neurodegenerative diseases, NOX inhibition may aim to primarily modulate the chronic inflammation that exacerbates disease progress. Future studies utilizing NOX inhibitors should pay attention to the acute or chronic nature or studied disease models. In the sections below, we discuss the utility of various isoform-specific and non-specific NOX inhibitors, as well as more challenges that still need to be met for successful translation to the clinics.

\section{Non-specific NOX inhibitors}

Apocynin Apocynin is perhaps the most studied drug of all the available NOX inhibitors. It was isolated from the medicinal plant Picrorhiza kurroa and inhibits NOX2 via preventing the membrane translocation of $\mathrm{p} 47 \mathrm{phox}$ and p67phox [315-320], without interfering with physiological intracellular killing and defense mechanisms [319]. Apocynin also reduces oxidative damage by scavenging hydrogen peroxide and hypochlorous acid in phagocytic cells [150, 321]. Apocynin inhibition of NOX in neutrophils was reported to require myeloperoxidase [150]. Some potential advantages of apocynin as a potential therapeutic agent in neurodegenerative disorders include its reported low toxicity and ability to pass 
the $\mathrm{BBB}[203,277,322]$, and its documented ability in Phase I clinical studies to reduce oxidative stress after aerosol administration [317, 323]. A potential disadvantage of apocynin as a therapeutic agent could be its reported "off target" direct ROS scavenging effects. However, as mentioned previously, apocynin-induced neuroprotection against ischemic injury has been shown to be lost in NOX2 knockout animals [157], suggesting its neuroprotective effects are NOX2 dependent. In addition, as a therapeutic agent, having other ROS inhibiting effects such as scavenging ROS may not necessary be a negative, as multimodal ROS inhibition could actually lead to a greater efficacy and improved therapeutic outcome.

DPI Diphenyleneiodonium chloride (DPI) has been used as an inhibitor of NOX in both in vivo and in vitro studies investigating oxidative stress in neurodegenerative disorders [145, 246, 247, 307]. DPI accepts an electron from flavin, thereby preventing the generation of ROS [324]. However, this mechanism of action allows DPI to inhibit other flavoenzymes. Thus, it is unlikely that DPI is selective for a specific NOX isoform. In addition to inhibiting NOX [325], DPI inhibits activities of NOS [326], xanthine oxidase, and cyp450 enzymes [246, 324], and blocks potassium and calcium currents [327], suggesting a nonselective ion channel blocking function that can protect neurons against glutamate excitotoxicity [328]. Despite its nonspecific action and high toxicity [329], at micromolar doses, DPI has been reported to inhibit NOX without any off target activities [330], opening the exploration of optimum dosage in evaluation of a drug's specificity for NOX. Nonetheless, development of more targeted approaches using specific NOX inhibitors is considered most needed by the field, so as to avoid inhibition of all NOX isoforms, which could lead to increased risk of negative side effects in patients.

\section{NOX2 specific inhibitors}

Gp91ds-tat Gp91ds-tat is reported to be a specific and efficacious peptide inhibitor that binds directly to NOX2 to impair its activity [249, 331]. Introduced in 2001, gp91ds-tat is a chimeric peptide that inhibits the association of p47phox with gp91phox and thus inhibits ROS production by NOX [249]. GP91ds-tat is specific for NOX2-containing gp91phox and not xanthine oxidase; however due to the homologous structure between NOX1 and NOX2, gp91ds-tat may also inhibit the assembly of NOX1 [249], as well as its activity [331]. In a cell free system, gp91ds-tat inhibits NOX activity up to $80 \%$, and does not act as a scavenger of superoxide, but this inhibition is reduced to roughly $35 \%$ in intact human neutrophils [249], possibly due to the cell's ability to overcome such an inhibition. Despite efficacy in animal models, gp91ds-tat has very limited oral bioavailability, and thus requires intravenous administration. It is also not clear whether it can pass the BBB.

GSK2795039 GSK2795039 is a novel, small molecule NOX2 inhibitor that has been shown to inhibit NOX2dependent ROS generation. In vitro characterization defined GSK2795039 as a reversible, direct inhibitor of NOX2, while in vivo studies showed brain penetrance with systemic administration [332]. This compound has been tested in a mouse model of acute pancreatitis to show reduced pancreatic cell necrosis [332] paralleling results found in gp91 ${ }^{\text {phox }}$ knock out mice [333]. However, preclinical studies are needed to test the efficacy of this novel small molecule NOX2 inhibitor in brain injury and neurodegenerative disorders.

\section{NOX selective inhibitors}

VAS2870 VAS2870 is a low molecular weight NOX inhibitor that can maintain basal ROS production in a model of endothelial cells [334] while decreasing ROS due to NOX. Though specific for NOX, VAS2870 does not appear to differentiate between specific NOX isoforms, including DUOX. Because of the variability in subunits amongst the NOX and DUOX enzymes, VAS2870 is thought to act on a common core flavocytochrome [335], but does not appear to inhibit other classes of flavoenzymes [70]. In an ischemic stroke animal model, administering VAS2870 intrathecally several hours after cerebral ischemia offered the same protection as deletion of NOX4, which was implicated as the source of ROS in this particular model [140]. However, VAS2870 has been reported to inhibit other NOX isoforms as well. For instance, in a liver tumor model, VAS2870 inhibited NOX1 [336], while it also inhibited DUOX-induced ROS in a model of zebrafish wound healing [337]. Additionally, there are some contradictions found in the mechanism of action of VAS2870. It has been cited to inhibit NOX2 in whole cell lysates [338], and even as a direct NOX2 inhibitor [339]; yet, another study suggests an inhibitory action upstream of NOX2 because the originally proposed NOX2 inhibition was not seen in a purified enzyme preparation [340]. A structurally similar analogue, VAS3947 shows higher solubility but is similarly nonspecific to the various NOX isoforms [70]. Though VAS2870 has been validated as an inhibitor of NOX, its lack of specificity to NOX isoforms, low solubility, and need for intrathecal route of administration make it unlikely to be successful for treatment of brain injury or neurodegenerative disorders in humans.

GKT-136901 Identified in 2010, GKT-136901 is a novel inhibitor of NOX that has high specificity for NOX1 and NOX4, with low affinity and partial inhibition of NOX2 
[341], and low affinity and low to no inhibition of other ROS producing enzymes [341, 342]. This novel dualinhibitor has also shown ability to scavenge peroxynitrite, which may prove useful therapeutically [343], but may confound studies utilizing GKT-136901 to investigate specific roles of NOX isoforms in disease pathology. GKT-136901 has high oral availability and in vivo plasma concentrations after administration [342], but its ability to pass the BBB is unclear. Since it is a selective NOX inhibitor and not single isoform specific, the potential for side effects may be increased.

GLX351322 A newly developed NOX inhibitor, GLX351322, is proposed to have relatively higher selectivity to NOX4 over NOX2. In a model of type 2 diabetes, GLX351322 treatment prevented ROS production and death in human islet cells [344]. Due to it only being recently developed, studies are needed to further confirm the specificity of this novel inhibitor and establish its ability to target NOX therapeutically in brain injury and neurodegenerative disorders.

\section{Translational challenges and emerging concepts}

While we have learned much about the biology, function and targeting of NOX subunits in the last decade, much more needs to be known. Several major challenges remain that must be met in order to translate basic discoveries in the field to effective therapies in the clinic. In the next section, we summarize these challenges and some potential solutions and future directions that may help move the field forward.

\section{The need for inducible, cell-type and NOX isoform specific knockout models}

All of the mutant animal studies discussed in this review used global knockout animal models. While these studies have yielded important insights, global knockout models are not without limitations. For instance, it is often difficult to distinguish primary versus secondary effects in global $\mathrm{KO}$ models. Furthermore, the knockout is lifelong, including throughout development, which could cause developmental confound and/or compensation issues. Finally, in global knockout animals the NOX gene is knocked out in multiple different cell types, and thus one cannot easily determine the role of a particular NOX- expressing cell type in a specific process or disorder. To address these limitations, the field would benefit from development of inducible, cell-specific NOX subunit knockout approaches in animal models of brain injury and neurodegenerative disorders. With the recent advent of CRISPR-Cas9 and related gene editing technologies, knockout model generation has become more cost effective and less time consuming, which should spur more rapid progress toward this goal. In addition to use of this technology in mice, it would be advantageous to also extend the inducible, conditional NOX knockout animal development to rats, so as to further confirm results in a different species.

\section{The challenge of developing specific NOX inhibitors that lack significant side effects}

An additional major challenge to the field is how to develop NOX inhibitors that avoid "off target" and nonspecific effects, and have reduced potential for negative side effects in patients. It has been suggested this may be achieved through development of isoform-specific inhibitors that target only a specific NOX isoform. Indeed, effort has already been devoted to development of such isoform-specific NOX inhibitors, which is expected to continue and grow. In addition to inhibitors, another possibility for isoform-specific NOX inhibition is siRNA knockdown. However, delivery of siRNAs to the brain is a challenge and requires more work and study before this would be a viable translational approach. Alternatively, a new approach that may yield effective isoformspecific NOX inhibitors is aptamer technology [345-348]. Aptamers are single-stranded nucleic acids that bind to their targets with high affinity and specificity and can directly block or interfere with the functions of the target proteins [348]. In addition, aptamers can be designed to penetrate the blood brain barrier [347, 349], can deliver additional therapeutic cargos (such as siRNA) to cells in a cell-type specific manner [346, 348, 350], and can be reversible [351]. Cell-type specific targeting could help avoid side effects by restricting inhibition to the major cell-type implicated in the pathology.

An additional therapeutic concern for most of the available NOX inhibitors is that they would inhibit both pathological and physiological NOX signaling. This is a significant concern, as inhibition of physiological NOX signaling could lead to significant side effects, especially when chronic NOX inhibition is utilized (which likely would be needed in chronic neurodegenerative disorders). Therefore, consideration must be given to strategies that would lead to interventions that would only inhibit pathological NOX signaling. This might be achieved by targeting critical interactions of NOX isoforms proteins with other proteins necessary for NOX to become active in pathological situations. Since aptamers have high specificity and affinity, and can be chemically modified to interfere with specific protein-protein interactions [352], aptamers technology might be one way to explore development of inhibitors that target only pathological NOX signaling. Furthermore, it is known that some NOX subunits require post-translational modification for activation [353]. Since aptamers can be designed to recognize post-translational modified sequences [348], they 
potentially could also be useful to inhibit posttranslationally "activated" NOX subunits.

\section{The challenge of balancing NOX activity for regenerative medicine}

While NOX activation has a role in the pathology of brain injury and neurodegenerative disorders, it is currently unknown whether it plays any role in regeneration of the brain after injury. Intriguingly, it is known that there is an increase in adult neurogenesis following various brain insults, including stroke [232, 354], TBI [233, 234], and even in certain stages of neurodegenerative disorders such as $\mathrm{AD}[235,236]$. Furthermore, recent work has shown that NOX2 is colocalized in neural stem cells in the subventricular zone, suggesting it may have a role in regulation of neurogenesis [241]. In support of this possibility, both in vivo and in vitro studies have recently shown that ROS generation and the activation of NOX enzyme are essential for the proliferation and self-renewal capacity of neural stem/progenitor cells [241, 242, 244, 245]. Under physiological conditions, it has been suggested that the ROS generation in the stem cell "niche" is mediated by NOX2, as (i) NOX2 expression was detected in neural stem cells and increased when these cells were stimulated with mitogen factors to promote proliferation [242, 245]; (ii) NOX2-deficient mice show decreased neurogenesis in the sub-ventricular zone and the dentate gyrus, two major regions well documented for adult neurogenesis [242, 244]; and (iii) cultured neural stem cells obtained from adult NOX2-deficient mice show decreased proliferation and self-renewal capacity [242, 244]. These studies only examined basal neurogenesis in a non-injury and non-neurodegenerative context. Given that brain injury can markedly elevate levels of ROS and NOX activation, additional studies are needed to examine whether NOX2-derived oxidative stress, influences the proliferation, self-renewal capacity, and cell-fate determination of both endogenous and exogenous neural stem cells following brain injury and in neurodegenerative disorders. Such studies could yield important new insights on the role of NOX in repair and regeneration of the brain, and help better inform future development strategies for therapeutic NOX intervention in brain injury and neurodegenerative disorders. Furthermore, the role of NOX in the vasculature needs to be considered when utilizing therapeutic NOX intervention. NOX enzymes are reported to promote angiogenesis: (i) NOX1 inhibition in endothelial cells reduce angiogenesis [355]; (ii) NOX4 is reported to have a protective role via enhancing proangiogenic signaling after hypoxia in cardiac tissue [356]; and (iii) BDNF induces NOX activation via p47phox phosphorylation promoted angiogenesis in vascular endothelial cells [357]. There may also be differential regulation of NOX isoforms in the vasculature in response to different neurodegenerative disorders, which may lead to variability in the potentially negative effects of utilizing non-selective NOX inhibitors. NOX inhibition has also been reported to affect synaptic plasticity and LTP induction [358]. Potential negative effects on the cerebrovasculature and neuroplasticity need to be considered when using NOX inhibitors. Despite potential pitfall of NOX inhibitors to alter physiological processes, it is important to note that apocynin has been used in clinical trials with low observed toxicity and no significant side effects [317, 323], supporting the continued pursuit of NOX inhibitors as potential therapy for neurodegenerative disorders.

\section{Conclusions}

There is significant evidence that NOX subunits and NOX activity are elevated in various neurodegenerative disorders, and that genetic ablation and pharmacological inhibition studies support the possibility of targeting NOX subunits for therapeutic benefit in neurodegenerative disorders. However, clearly there still remain many challenges ahead for the discovery of effective and NOXspecific targeting that would yield benefit in neurodegenerative disorders while minimizing negative side effects and generating a healthy neuronal environment for neurogenesis. While addressing these challenges remains problematic, the continued advancement of technology offers hope that realization of this goal may be achievable in the near future.

\section{Abbreviations \\ AD: Alzheimer's disease; ALS: Amyotrophic lateral sclerosis; A $\beta$ : Beta-amyloid; CNS: Central nervous system; DNA: Deoxyribonucleic acid; DPI: Diphenyleneiodonium chloride; DUOX: Dual oxidase; EAE: Experimental autoimmune encephalomyelitis; FAD: Flavin adenine dinucleotide; HD: Huntington's disease; JNK: Jun-N-terminal kinase; MAPK: Mitogen- activated protein kinases; MS: Multiple sclerosis; NADPH: Nicotinamide adenine dinucleotide phosphate; NFkb: Nuclear factor-kappa-b; NOX: NADPH oxidase; NOXA1: NADPH oxidase activator 1; NOXO1: NADPH oxidase organizer 1; PD: Parkinson's disease; phox: Phagocytic oxidase; \\ PI3K: Phosphoinositide-3 kinase; PKA: Protein kinase A; PKB: Protein kinase B; PKC: Protein kinase C; PMCAO: Permanent middle cerebral artery occlusion; RNS: Reactive nitrogen species; ROS: Reactive oxygen species; TBI: Traumatic brain injury; tMCAO: Transient middle cerebral artery occlusion}

\section{Acknowledgements}

Not applicable.

\section{Funding}

This research was supported in part by a VA Merit Review Award (5l101BX001117) from the United States Department of Veteran's Affairs, Biomedical Laboratory Research and Development Service, and research grants (5R01NS050730, R01NS088058) from the National Institutes of Neurological Disorders and Stroke, National Institutes of Health, United States of America.

\section{Availability of data and materials}

Not applicable.

Authors' contributions

MWM and DWB wrote the manuscript. JW, QZ, RW, KMD, and RKV provided intellectual input and editorial suggestions. All authors read and approved the final manuscript. 


\section{Competing interests}

The authors declare that they have no competing interests.

\section{Consent for publication}

All authors agree to the publication.

\section{Ethics approval and consent to participate}

Not applicable.

\section{US Government Disclaimer}

"The contents do not represent the views of the U.S. Department of Veteran Affairs or the United States Government."

\section{Author details}

${ }^{1}$ Charlie Norwood VA Medical Center, One Freedom Way, Augusta, GA 30904, USA. ²Department of Neuroscience and Regenerative Medicine, Medical College of Georgia, 1120 Fifteenth Street, Augusta, GA 30912, USA. ${ }^{3}$ Department of Neurosurgery, Medical College of Georgia, Augusta University, 1120 Fifteenth Street, Augusta, GA 30912, USA. ${ }^{4}$ Department of Obstetrics and Gynecology, University of Texas Health Science Center, 7703 Medical Drive, San Antonio, TX 78229, USA

Received: 3 November 2016 Accepted: 5 January 2017

Published online: 17 January 2017

\section{References}

1. Global Burden of Disease Study C. Global, regional, and national incidence, prevalence, and years lived with disability for 301 acute and chronic diseases and injuries in 188 countries, 1990-2013: a systematic analysis for the Global Burden of Disease Study 2013. Lancet. 2015;386:743-800.

2. Whiteford HA, Ferrari AJ, Degenhardt L, Feigin V, Vos T. The global burden of mental, neurological and substance use disorders: an analysis from the global burden of disease study 2010. PLoS One. 2015;10:e0116820.

3. Kowal SL, Dall TM, Chakrabarti R, Storm MV, Jain A. The current and projected economic burden of Parkinson's disease in the United States. Mov Disord. 2013;28:311-8.

4. Murray CJ, Atkinson C, Bhalla K, Birbeck G, Burstein R, Chou D, Dellavalle R, Danaei G, Ezzati M, Fahimi A, et al. The state of US health, 1990-2010: burden of diseases, injuries, and risk factors. JAMA. 2013;310:591-608.

5. Bennett DA, Krishnamurthi RV, Barker-Collo S, Forouzanfar MH, Naghavi M, Connor M, Lawes CM, Moran AE, Anderson LM, Roth GA, et al. The global burden of ischemic stroke: findings of the GBD 2010 study. Glob Heart. 2014;9:107-12

6. Rubiano AM, Carney N, Chesnut R, Puyana JC. Global neurotrauma research challenges and opportunities. Nature. 2015;527:193-7.

7. Chiurchiu V, Orlacchio A, Maccarrone M. Is modulation of oxidative stress an answer? the state of the Art of redox therapeutic actions in neurodegenerative diseases. Oxid Med Cell Longev. 2016:2016:7909380.

8. Guo C, Sun L, Chen X, Zhang D. Oxidative stress, mitochondrial damage and neurodegenerative diseases. Neural Regen Res. 2013:8:2003-14.

9. Kim GH, Kim JE, Rhie SJ, Yoon S. The role of oxidative stress in neurodegenerative diseases. Exp Neurobiol. 2015;24:325-40.

10. Cobb CA, Cole MP. Oxidative and nitrative stress in neurodegeneration. Neurobiol Dis. 2015;84:4-21.

11. Gao HM, Zhou H, Hong JS. NADPH oxidases: novel therapeutic targets for neurodegenerative diseases. Trends Pharmacol Sci. 2012;33:295-303.

12. Bedard $\mathrm{K}$, Krause $\mathrm{KH}$. The NOX family of ROS-generating NADPH oxidases: physiology and pathophysiology. Physiol Rev. 2007:87:245-313.

13. Nayernia Z, Jaquet $\mathrm{V}$, Krause KH. New insights on NOX enzymes in the central nervous system. Antioxid Redox Signal. 2014;20:2815-37.

14. Lambeth JD, Neish AS. Nox enzymes and new thinking on reactive oxygen: a double-edged sword revisited. Annu Rev Pathol. 2014;9:119-45.

15. Grivennikova VG, Vinogradov AD. Partitioning of superoxide and hydrogen peroxide production by mitochondrial respiratory complex I. Biochim Biophys Acta. 1827;2013:446-54.

16. Nakamura T, Prikhodko OA, Pirie E, Nagar S, Akhtar MW, Oh CK, McKercher SR, Ambasudhan R, Okamoto S, Lipton SA. Aberrant protein S-nitrosylation contributes to the pathophysiology of neurodegenerative diseases. Neurobiol Dis. 2015;84:99-108.

17. Beckman JS, Koppenol WH. Nitric oxide, superoxide, and peroxynitrite: the good the bad, and ugly. Am J Physiol. 1996;271:1424-37.
18. McCord JM, Fridovich I. Superoxide dismutase. An enzymic function for erythrocuprein (hemocuprein). J Biol Chem. 1969;244:6049-55.

19. Maraldi T. Natural compounds as modulators of NADPH oxidases. Oxid Med Cell Longev. 2013;2013:10.

20. Riley PA. Free radicals in biology: oxidative stress and the effects of ionizing radiation. Int J Radiat Biol. 1994:65:27-33.

21. Benov L. How superoxide radical damages the cell. Protoplasma. 2001;217:33-6.

22. Forman HJ, Torres M. Reactive oxygen species and cell signaling: respiratory burst in macrophage signaling. Am J Respir Crit Care Med. 2002;166:54-8.

23. Sastre J, Pallardó FV, Viña J. The role of mitochondrial oxidative stress in aging. Free Radic Biol Med. 2003;35:1-8.

24. Zekry D, Epperson TK, Krause K-H. A role for NOX NADPH oxidases in Alzheimer's disease and other types of dementia? IUBMB Life. 2003;55:307-13.

25. Federico A, Cardaioli E, Da Pozzo P, Formichi P, Gallus GN, Radi E. Mitochondria, oxidative stress and neurodegeneration. J Neurol Sci. 2012:322:254-62.

26. Bhat AH, Dar KB, Anees S, Zargar MA, Masood A, Sofi MA, Ganie SA. Oxidative stress, mitochondrial dysfunction and neurodegenerative diseases; a mechanistic insight. Biomed Pharmacother. 2015;74:101-10.

27. Shyu KG, Chang CC, Yeh YC, Sheu JR, Chou DS. Mechanisms of ascorby radical formation in human platelet-rich plasma. Biomed Res Int. 2014; 2014:614506.

28. Coso S, Harrison I, Harrison CB, Vinh A, Sobey CG, Drummond GR, Williams ED, Selemidis S. NADPH oxidases as regulators of tumor angiogenesis: current and emerging concepts. Antioxid Redox Signal. 2012;16:1229-47.

29. Selemidis S, Sobey CG, Wingler K, Schmidt HH, Drummond GR. NADPH oxidases in the vasculature: molecular features, roles in disease and pharmacological inhibition. Pharmacol Ther. 2008;120:254-91.

30. Armitage ME, Wingler K, Schmidt HH, La M. Translating the oxidative stress hypothesis into the clinic: NOX versus NOS. J Mol Med (Berl). 2009:87:1071-6.

31. Kroller-Schon S, Steven S, Kossmann S, Scholz A, Daub S, Oelze M, Xia N Hausding M, Mikhed Y, Zinssius E, et al. Molecular mechanisms of the crosstalk between mitochondria and NADPH oxidase through reactive oxygen species-studies in white blood cells and in animal models. Antioxid Redox Signal. 2014;20:247-66.

32. Schulz E, Wenzel P, Munzel T, Daiber A. Mitochondrial redox signaling: Interaction of mitochondrial reactive oxygen species with other sources of oxidative stress. Antioxid Redox Signal. 2014;20:308-24.

33. Daiber A, Di Lisa F, Oelze M, Kroller-Schon S, Steven S, Schulz E, Munzel T. Crosstalk of mitochondria with NADPH oxidase via reactive oxygen and nitrogen species signalling and its role for vascular function. Br J Pharmacol. 2015:13403. [Epub ahead of print].

34. Dupuy C, Ohayon R, Valent A, Noël-Hudson MS, Dème D, Virion A Purification of a novel flavoprotein involved in the thyroid NADPH oxidase. Cloning of the porcine and human cdnas. J Biol Chem. 1999;274:37265-9.

35. Cheng G, Cao Z, Xu X, van Meir EG, Lambeth JD. Homologs of gp91 phox: cloning and tissue expression of Nox3, Nox4, and Nox5. Gene. 2001;269:131-40.

36. Stasia MJ, Li XJ. Genetics and immunopathology of chronic granulomatous disease. Semin Immunopathol. 2008;30:209-35

37. De Deken X, Wang D, Many MC, Costagliola S, Libert F, Vassart G, Dumont JE, Miot F. Cloning of two human thyroid CDNAs encoding new members of the NADPH oxidase family. J Biol Chem. 2000:275:23227-33.

38. Geiszt M, Leto TL. The Nox family of NAD(P)H oxidases: host defense and beyond. J Biol Chem. 2004:279:51715-8.

39. Pendyala S, Natarajan $V$. Redox regulation of Nox proteins. Respir Physiol Neurobiol. 2010:174:265-71.

40. Ueyama T, Geiszt M, Leto TL. Involvement of Rac1 in activation of multicomponent Nox1- and Nox3-based NADPH oxidases. Mol Cell Biol. 2006;26:2160-74.

41. Cheng G, Diebold BA, Hughes Y, Lambeth JD. Nox1-dependent reactive oxygen generation is regulated by Rac1. J Biol Chem. 2006;281:17718-26.

42. Suh YA, Arnold RS, Lassegue B, Shi J, Xu X, Sorescu D, Chung AB, Griendling KK, Lambeth JD. Cell transformation by the superoxide-generating oxidase Mox1. Nature. 1999;401:79-82.

43. Banfi B, Clark RA, Steger K, Krause KH. Two novel proteins activate superoxide generation by the NADPH oxidase NOX1. J Biol Chem. 2003;278:3510-3.

44. Cheng $G$, Lambeth JD. NOXO1, regulation of lipid binding, localization, and activation of Nox1 by the Phox homology (PX) domain. J Biol Chem. 2004; 279:4737-42.

45. Yamamoto A, Takeya R, Matsumoto M, Nakayama Kl, Sumimoto H. Phosphorylation of Noxo1 at threonine 341 regulates its interaction with Noxal and the superoxide-producing activity of Nox1. FEBS J. 2013;280:5145-59. 
46. Kroviarski Y, Debbabi M, Bachoual R, Perianin A, Gougerot-Pocidalo MA, ElBenna J, Dang PM. Phosphorylation of NADPH oxidase activator 1 (NOXA1) on serine 282 by MAP kinases and on serine 172 by protein kinase $C$ and protein kinase A prevents NOX1 hyperactivation. FASEB J. 2010;24:2077-92.

47. Brandes RP, Schroder K. NOXious phosphorylation: Smooth muscle reactive oxygen species production is facilitated by direct activation of the NADPH oxidase Nox1. Circ Res. 2014;115:898-900.

48. Streeter J, Schickling BM, Jiang S, Stanic B, Thiel WH, Gakhar L, Houtman JC, Miller Jr FJ. Phosphorylation of Nox1 regulates association with NoxA1 activation domain. Circ Res. 2014;115:911-8.

49. Madrigal-Matute J, Fernandez-Garcia CE, Gomez-Guerrero C, Lopez-Franco O, Munoz-Garcia B, Egido J, Blanco-Colio LM, Martin-Ventura JL. HSP90 inhibition by 17-DMAG attenuates oxidative stress in experimental atherosclerosis. Cardiovasc Res. 2012;95:116-23.

50. Skurlova M, Stofkova A, Jurcovicova J. Anxiety-like behavior in the elevatedplus maze tests and enhanced IL-1 beta, IL-6, NADPH oxidase-1, and iNOS mRNAs in the hippocampus during early stage of adjuvant arthritis in rats. Neurosci Lett. 2011;487:250-4.

51. Goyal P, Weissmann N, Grimminger F, Hegel C, Bader L, Rose F, Fink L, Ghofrani HA, Schermuly RT, Schmidt HH, et al. Upregulation of $\mathrm{NAD}(\mathrm{P}) \mathrm{H}$ oxidase 1 in hypoxia activates hypoxia-inducible factor 1 via increase in reactive oxygen species. Free Radic Biol Med. 2004;36:1279-88.

52. Chen F, Pandey D, Chadli A, Catravas JD, Chen T, Fulton DJ. Hsp90 regulates NADPH oxidase activity and is necessary for superoxide but not hydrogen peroxide production. Antioxid Redox Signal. 2011;14:2107-19.

53. Savchenko VL. Regulation of NADPH oxidase gene expression with PKA and cytokine IL-4 in neurons and microglia. Neurotox Res. 2013;23:201-13.

54. Mead EL, Mosley A, Eaton S, Dobson L, Heales SJ, Pocock JM. Microglial neurotransmitter receptors trigger superoxide production in microglia; consequences for microglial-neuronal interactions. J Neurochem. 2012; 121:287-301.

55. Miller Jr FJ, Chu X, Stanic B, Tian X, Sharma RV, Davisson RL, Lamb FS. A differential role for endocytosis in receptor-mediated activation of Nox1. Antioxid Redox Signal. 2010;12:583-93.

56. Park HS, Lee SH, Park D, Lee JS, Ryu SH, Lee WJ, Rhee SG, Bae YS. Sequentia activation of phosphatidylinositol 3-kinase, beta Pix, Rac1, and Nox1 in growth factor-induced production of H2O2. Mol Cell Biol. 2004;24:4384-94.

57. Lassegue B, Sorescu D, Szocs K, Yin Q, Akers M, Zhang Y, Grant SL, Lambeth JD, Griendling KK. Novel gp91(phox) homologues in vascular smooth muscle cells : nox1 mediates angiotensin II-induced superoxide formation and redox-sensitive signaling pathways. Circ Res. 2001;88:888-94.

58. Seshiah PN, Weber DS, Rocic P, Valppu L, Taniyama Y, Griendling KK Angiotensin II stimulation of NAD(P)H oxidase activity: upstream mediators. Circ Res. 2002;91:406-13.

59. Jackman KA, Miller AA, Drummond GR, Sobey CG. Importance of NOX1 for angiotensin II-induced cerebrovascular superoxide production and cortical infarct volume following ischemic stroke. Brain Res. 2009;1286:215-20.

60. Jin R, Song Z, Yu S, Piazza A, Nanda A, Penninger JM, Granger DN, Li G. Phosphatidylinositol-3-kinase gamma plays a central role in bloodbrain barrier dysfunction in acute experimental stroke. Stroke. 2011; 42:2033-44

61. Cheret C, Gervais A, Lelli A, Colin C, Amar L, Ravassard P, Mallet J, Cumano $\mathrm{A}$, Krause $\mathrm{KH}$, Mallat $\mathrm{M}$. Neurotoxic activation of microglia is promoted by a nox1-dependent NADPH oxidase. J Neurosci. 2008;28:12039-51.

62. Ibi M, Matsuno K, Shiba D, Katsuyama M, Iwata K, Kakehi T, Nakagawa T, Sango K, Shirai Y, Yokoyama T, et al. Reactive oxygen species derived from NOX1/ NADPH oxidase enhance inflammatory pain. J Neurosci. 2008;28:9486-94.

63. Ibi M, Katsuyama M, Fan C, Iwata K, Nishinaka T, Yokoyama T, YabeNishimura C. NOX1/NADPH oxidase negatively regulates nerve growth factor-induced neurite outgrowth. Free Radic Biol Med. 2006;40:1785-95.

64. Brown DI, Griendling KK. Nox proteins in signal transduction. Free Radic Biol Med. 2009;47:1239-53.

65. Takeya R, Ueno N, Kami K, Taura M, Kohjima M, Izaki T, Nunoi H, Sumimoto $H$. Novel human homologues of p47phox and p67phox participate in activation of superoxide-producing NADPH oxidases. J Biol Chem. 2003; 278:25234-46.

66. Segal AW, Shatwell KP. The NADPH oxidase of phagocytic leukocytes. Ann N Y Acad Sci. 1997:832:215-22.

67. Chrissobolis S, Banfi B, Sobey CG, Faraci FM. Role of Nox isoforms in angiotensin II-induced oxidative stress and endothelial dysfunction in brain. J Appl Physiol. 2012;113:184-91.
68. Brennan-Minnella AM, Shen Y, El-Benna J, Swanson RA. Phosphoinositide 3-kinase couples NMDA receptors to superoxide release in excitotoxic neuronal death. Cell Death Dis. 2013:4:e580.

69. Brandes RP. Role of NADPH oxidases in the control of vascular gene expression. Antioxid Redox Signal. 2003;5:803-11.

70. Altenhöfer S, Kleikers PWM, Radermacher KA, Scheurer P, Rob Hermans J J Schiffers $\mathrm{P}, \mathrm{Ho}$ H, Wingler $\mathrm{K}$, Schmidt HHHW. The NOX toolbox: validating the role of NADPH oxidases in physiology and disease. Cell Mol Life Sci. 2012;69:2327-43.

71. Cooney SJ, Bermudez-Sabogal SL, Byrnes KR. Cellular and temporal expression of NADPH oxidase (NOX) isotypes after brain injury. J Neuroinflammation. 2013;10:155.

72. Perry VH, Nicoll JA, Holmes C. Microglia in neurodegenerative disease. Nat Rev Neurol. 2010;6:193-201.

73. Cairns B, Kim JY, Tang XN, Yenari MA. NOX inhibitors as a therapeutic strategy for stroke and neurodegenerative disease. Curr Drug Targets. 2012; 13:199-206.

74. Johnson JL, Park JW, Benna JE, Faust LP, Inanami O, Babior BM. Activation of p47(PHOX), a cytosolic subunit of the leukocyte NADPH oxidase. Phosphorylation of ser-359 or ser-370 precedes phosphorylation at other sites and is required for activity. J Biol Chem. 1998;273:35147-52.

75. Surace MJ, Block ML. Targeting microglia-mediated neurotoxicity: the potential of NOX2 inhibitors. Cell Mol Life Sci. 2012;69:2409-27.

76. Diekmann D, Abo A, Johnston C, Segal AW, Hall A. Interaction of Rac with p67phox and regulation of phagocytic NADPH oxidase activity. Science. 1994;265:531-3.

77. Pick E. Role of the Rho GTPase Rac in the activation of the phagocyte NADPH oxidase: outsourcing a key task. Small GTPases. 2014;5:e27952.

78. Kao YY, Gianni D, Bohl B, Taylor RM, Bokoch GM. Identification of a conserved Rac-binding site on NADPH oxidases supports a direct GTPase regulatory mechanism. J Biol Chem. 2008;283:12736-46.

79. Li J-M, Shah AM. Intracellular localization and preassembly of the NADPH oxidase complex in cultured endothelial cells. J Biol Chem. 2002;277:19952-60.

80. Li J-M, Fan LM, Christie MR, Shah AM. Acute tumor necrosis factor alpha signaling via NADPH oxidase in microvascular endothelial cells: role of p47phox phosphorylation and binding to TRAF4. Mol Cell Biol. 2005; 25:2320-30

81. Li J-M, Mullen AM, Yun S, Wientjes F, Brouns GY, Thrasher AJ, Shah AM. Essential role of the NADPH oxidase subunit p47(phox) in endothelial cell superoxide production in response to phorbol ester and tumor necrosis factor-alpha. Circ Res. 2002;90:143-50.

82. Li J-M, Shah AM. Mechanism of endothelial cell NADPH oxidase activation by angiotensin II. Role of the p47phox subunit. J Biol Chem. 2003;278:12094-100.

83. Brennan-Minnella AM, Won SJ, Swanson RA. NADPH oxidase-2: linking glucose, acidosis, and excitotoxicity in stroke. Antioxid Redox Signal. 2015; 22:161-74.

84. Lam TI, Brennan-Minnella AM, Won SJ, Shen Y, Hefner C, Shi Y, Sun D, Swanson RA. Intracellular pH reduction prevents excitotoxic and ischemic neuronal death by inhibiting NADPH oxidase. Proc Natl Acad Sci U S A. 2013;110:E4362-4368.

85. Raz L, Zhang QG, Zhou CF, Han D, Gulati P, Yang LC, Yang F, Wang RM, Brann DW. Role of Rac1 GTPase in NADPH oxidase activation and cognitive impairment following cerebral ischemia in the rat. PLoS One. 2010;5:e12606.

86. Kim GS, Jung JE, Niizuma K, Chan PH. CK2 is a novel negative regulator of $\mathrm{NADPH}$ oxidase and a neuroprotectant in mice after cerebral ischemia. J Neurosci. 2009;29:14779-89.

87. Yuan G, Khan SA, Luo W, Nanduri J, Semenza GL, Prabhakar NR. Hypoxiainducible factor 1 mediates increased expression of NADPH oxidase-2 in response to intermittent hypoxia. J Cell Physiol. 2011;226:2925-33.

88. Bianca VD, Dusi S, Bianchini E, Dal Pra I, Rossi F. beta-amyloid activates the O-2 forming NADPH oxidase in microglia, monocytes, and neutrophils. A possible inflammatory mechanism of neuronal damage in Alzheimer's disease. J Biol Chem. 1999;274:15493-9.

89. Jana A, Pahan K. Fibrillar amyloid-beta peptides kill human primary neurons via NADPH oxidase-mediated activation of neutral sphingomyelinase. Implications for Alzheimer's disease. J Biol Chem. 2004;279:51451-9.

90. Fan L, Sawbridge D, George V, Teng L, Bailey A, Kitchen I, Li JM. Chronic cocaine-induced cardiac oxidative stress and mitogen-activated protein kinase activation: the role of Nox2 oxidase. J Pharmacol Exp Ther. 2009;328:99-106.

91. Furst R, Brueckl C, Kuebler WM, Zahler S, Krotz F, Gorlach A, Vollmar AM, Kiemer AK. Atrial natriuretic peptide induces mitogen-activated protein 
kinase phosphatase-1 in human endothelial cells via Rac1 and NAD(P)H oxidase/Nox2-activation. Circ Res. 2005;96:43-53.

92. Borchi E, Parri M, Papucci L, Becatti M, Nassi N, Nassi P, Nediani C. Role of $\mathrm{NADPH}$ oxidase in $\mathrm{H} 9 \mathrm{c} 2$ cardiac muscle cells exposed to simulated ischaemia-reperfusion. J Cell Mol Med. 2009;13:2724-35.

93. Yuan H, Zhang X, Huang X, Lu Y, Tang W, Man Y, Wang S, Xi J, Li J. NADPH oxidase 2-derived reactive oxygen species mediate FFAs-induced dysfunction and apoptosis of beta-cells via JNK, p38 MAPK and p53 pathways. PLoS One. 2010;5:e15726.

94. Hingtgen SD, Tian X, Yang J, Dunlay SM, Peek AS, Wu Y, Sharma RV, Engelhardt JF, Davisson RL. Nox2-containing NADPH oxidase and Akt activation play a key role in angiotensin I--induced cardiomyocyte hypertrophy. Physiol Genomics. 2006:26:180-91.

95. Bae YS, Sung JY, Kim OS, Kim YJ, Hur KC, Kazlauskas A, Rhee SG. Plateletderived growth factor-induced $\mathrm{H}(2) \mathrm{O}(2)$ production requires the activation of phosphatidylinositol 3-kinase. J Biol Chem. 2000;275:10527-31.

96. Li Q, Spencer NY, Oakley FD, Buettner GR, Engelhardt JF. Endosomal Nox2 facilitates redox-dependent induction of NF-kappaB by TNF-alpha. Antioxid Redox Signal. 2009;11:1249-63.

97. San Jose G, Bidegain J, Robador PA, Diez J, Fortuno A, Zalba G. Insulininduced NADPH oxidase activation promotes proliferation and matrix metalloproteinase activation in monocytes/macrophages. Free Radic Biol Med. 2009;46:1058-67.

98. Cahill-Smith S, Li J-M. Oxidative stress, redox signalling and endothelial dysfunction in ageing-related neurodegenerative diseases: a role of NADPH oxidase 2. Br J Clin Pharmacol. 2014;78:441-53.

99. Li JM, Fan LM, George VT, Brooks G. Nox2 regulates endothelial cell cycle arrest and apoptosis via p21cip1 and p53. Free Radic Biol Med. 2007;43:976-86.

100. Bánfi B, Malgrange B, Knisz J, Steger K, Dubois-Dauphin M, Krause K-H. NOX3, a superoxide-generating NADPH oxidase of the inner ear. J Biol Chem. 2004;279:46065-72.

101. Kahles T, Brandes RP. Which NADPH oxidase isoform is relevant for ischemic stroke? The case for nox 2. Antioxid Redox Signal. 2013;18:1400-17.

102. Paffenholz R, Bergstrom RA, Pasutto F, Wabnitz P, Munroe RJ, Jagla W, Heinzmann U, Marquardt A, Bareiss A, Laufs J, et al. Vestibular defects in head-tilt mice result from mutations in Nox3, encoding an NADPH oxidase. Genes Dev. 2004;18:486-91.

103. Vlajkovic SM, Lin SC-Y, Wong ACY, Wackrow B, Thorne PR. Noise-induced changes in expression levels of NADPH oxidases in the cochlea. Hear Res. 2013;304:145-52.

104. Leto TL, Morand S, Hurt D, Ueyama T. Targeting and regulation of reactive oxygen species generation by Nox family NADPH oxidases. Antioxid Redox Signal. 2009;11:2607-19.

105. Ueno N, Takeya R, Miyano K, Kikuchi H, Sumimoto H. The NADPH oxidase Nox3 constitutively produces superoxide in a p22phox-dependent manner: its regulation by oxidase organizers and activators. J Biol Chem. 2005;280:23328-39.

106. Nakano Y, Banfi B, Jesaitis AJ, Dinauer MC, Allen L-AH, Nauseef WM. Critical roles for p22phox in the structural maturation and subcellular targeting of Nox3. Biochem J. 2007:403:97-108.

107. Nisimoto Y, Jackson HM, Ogawa H, Kawahara T, Lambeth JD. Constitutive NADPH-dependent electron transferase activity of the Nox4 dehydrogenase domain. Biochemistry. 2010;49:2433-42.

108. Martyn KD, Frederick LM, von Loehneysen K, Dinauer MC, Knaus UG. Functional analysis of Nox4 reveals unique characteristics compared to other NADPH oxidases. Cell Signal. 2006;18:69-82.

109. Serrander L, Cartier L, Bedard K, Banfi B, Lardy B, Plastre O, Sienkiewicz A, Fórró L, Schlegel W, Krause K-H. NOX4 activity is determined by mRNA levels and reveals a unique pattern of ROS generation. Biochem J. 2007:406:105-14.

110. Kuroda J, Ago T, Nishimura A, Nakamura K, Matsuo R, Wakisaka Y, Kamouchi $\mathrm{M}$, Kitazono T. Nox4 is a major source of superoxide production in human brain pericytes. J Vasc Res. 2014;51:429-38.

111. Lyle AN, Deshpande NN, Taniyama Y, Seidel-Rogol B, Pounkova L, Du P, Papaharalambus C, Lassegue B, Griendling KK. Poldip2, a novel regulator of Nox4 and cytoskeletal integrity in vascular smooth muscle cells. Circ Res. 2009;105:249-59.

112. Janiszewski M, Lopes LR, Carmo AO, Pedro MA, Brandes RP, Santos CX, Laurindo FR. Regulation of $\mathrm{NAD}(\mathrm{P}) \mathrm{H}$ oxidase by associated protein disulfide isomerase in vascular smooth muscle cells. J Biol Chem. 2005;280:40813-9.

113. Diaz B, Shani G, Pass I, Anderson D, Quintavalle M, Courtneidge SA. Tks5dependent, nox-mediated generation of reactive oxygen species is necessary for invadopodia formation. Sci Signal. 2009;2:ra53.
114. Desai LP, Zhou Y, Estrada AV, Ding Q, Cheng G, Collawn JF, Thannickal VJ. Negative regulation of NADPH oxidase 4 by hydrogen peroxide-inducible clone 5 (Hic-5) protein. J Biol Chem. 2014;289:18270-8.

115. Fulton DJ. Nox5 and the regulation of cellular function. Antioxid Redox Signal. 2009;11:2443-52.

116. Antony S, Wu Y, Hewitt SM, Anver MR, Butcher D, Jiang G, Meitzler JL, Liu H, Juhasz A, Lu J, et al. Characterization of NADPH oxidase 5 expression in human tumors and tumor cell lines with a novel mouse monoclonal antibody. Free Radic Biol Med. 2013;65:497-508.

117. Kawahara T, Jackson HM, Smith SM, Simpson PD, Lambeth JD. Nox5 forms a functional oligomer mediated by self-association of its dehydrogenase domain. Biochemistry. 2011;50:2013-25.

118. Jagnandan D, Church JE, Banfi B, Stuehr DJ, Marrero MB, Fulton DJR. Novel mechanism of activation of NADPH oxidase 5. calcium sensitization via phosphorylation. J Biol Chem. 2007;282:6494-507.

119. Grasberger $H$, Refetoff S. Identification of the maturation factor for dual oxidase. Evolution of an eukaryotic operon equivalent. J Biol Chem. 2006; 281:18269-72.

120. Moreno JC, Bikker H, Kempers MJ, van Trotsenburg AS, Baas F, de Vijlder رل Vulsma T, Ris-Stalpers C. Inactivating mutations in the gene for thyroid oxidase 2 (THOX2) and congenital hypothyroidism. N Engl J Med. 2002;347:95-102.

121. Hristova M, Habibovic A, Veith $C$, Janssen-Heininger YM, Dixon AE, Geiszt M, van der Vliet A. Airway epithelial dual oxidase 1 mediates allergen-induced IL-33 secretion and activation of type 2 immune responses. J Allergy Clin Immunol. 2015;137:1545-56.

122. Ameziane-El-Hassani R, Talbot M, de Souza Dos Santos MC, Al Ghuzlan A, Hartl D, Bidart JM, De Deken X, Miot F, Diallo I, de Vathaire F, et al. NADPH oxidase DUOX1 promotes long-term persistence of oxidative stress after an exposure to irradiation. Proc Natl Acad Sci U S A. 2015;112:5051-6.

123. Ling Q, Shi W, Huang C, Zheng J, Cheng Q, Yu K, Chen S, Zhang H, Li N, Chen $\mathrm{M}$. Epigenetic silencing of dual oxidase 1 by promoter hypermethylation in human hepatocellular carcinoma. Am J Cancer Res. 2014:4:508-17.

124. Ko E, Choi H, Park KN, Park JY, Lee TR, Shin DW, Bae YS. Dual oxidase 2 is essential for house dust mite-induced pro-inflammatory cytokine production in human keratinocytes. Exp Dermatol. 2015;24:936-41.

125. Kim MJ, Ryu JC, Kwon Y, Lee S, Bae YS, Yoon JH, Ryu JH. Dual oxidase 2 in lung epithelia is essential for hyperoxia-induced acute lung injury in mice. Antioxid Redox Signal. 2014;21:1803-18.

126. Marrinan S, Emmanuel AV, Burn DJ. Delayed gastric emptying in Parkinson's disease. Mov Disord. 2014;29:23-32

127. Shelat PB, Chalimoniuk M, Wang JH, Strosznajder JB, Lee JC, Sun AY, Simonyi A, Sun GY. Amyloid beta peptide and NMDA induce ROS from NADPH oxidase and AA release from cytosolic phospholipase A2 in cortical neurons. J Neurochem. 2008;106:45-55.

128. Zhang W, Wang T, Pei Z, Miller DS, Wu X, Block ML, Wilson B, Zhang W, Zhou Y, Hong JS, Zhang J. Aggregated alpha-synuclein activates microglia: a process leading to disease progression in Parkinson's disease. FASEB J. 2005;19:533-42.

129. Chen H, Yoshioka H, Kim GS, Jung JE, Okami N, Sakata H, Maier CM, Narasimhan P, Goeders CE, Chan PH. Oxidative stress in ischemic brain damage: mechanisms of cell death and potential molecular targets for neuroprotection. Antioxid Redox Signal. 2011;14:1505-17.

130. Chan PH. Reactive oxygen radicals in signaling and damage in the ischemic brain. J Cereb Blood Flow Metab. 2001;21:2-14.

131. Chen H, Song YS, Chan PH. Inhibition of NADPH oxidase is neuroprotective after ischemia-reperfusion. J Cereb Blood Flow Metab. 2009;29:1262-72.

132. Zhang Q-G, Raz L, Wang R, Han D, De Sevilla L, Yang F, Vadlamudi RK, Brann DW. Estrogen attenuates ischemic oxidative damage via an estrogen receptor alpha-mediated inhibition of NADPH oxidase activation. J Neurosci. 2009;29:13823-36

133. Zhang QG, Laird MD, Han D, Nguyen K, Scott E, Dong Y, Dhandapani KM, Brann DW. Critical role of NADPH oxidase in neuronal oxidative damage and microglia activation following traumatic brain injury. PLoS One. 2012;7:e34504.

134. Yoshioka H, Niizuma K, Katsu M, Okami N, Sakata H, Kim GS, Narasimhan P, Chan PH. NADPH oxidase mediates striatal neuronal injury after transient global cerebral ischemia. J Cereb Blood Flow Metab. 2011;31:868-80.

135. Li H, Wang Y, Feng D, Liu Y, Xu M, Gao A, Tian F, Zhang L, Cui Y, Wang Z, Chen $\mathrm{G}$. Alterations in the time course of expression of the Nox family in the brain in a rat experimental cerebral ischemia and reperfusion model: effects of melatonin. J Pineal Res. 2014;57:110-9. 
136. Zhang HF, Li TB, Liu B, Lou Z, Zhang JJ, Peng JJ, Zhang XJ, Ma QL, Peng J, Luo XJ. Inhibition of myosin light chain kinase reduces NADPH oxidasemediated oxidative injury in rat brain following cerebral ischemia/ reperfusion. Naunyn Schmiedebergs Arch Pharmacol. 2015;388:953-63.

137. Liu H, Wei X, Kong L, Liu X, Cheng L, Yan S, Zhang X, Chen L. NOD2 is involved in the inflammatory response after cerebral ischemia-reperfusion injury and triggers NADPH oxidase 2-derived reactive oxygen species. Int Biol Sci. 2015;11:525-35.

138. Hong H, Zeng JS, Kreulen DL, Kaufman DI, Chen AF. Atorvastatin protects against cerebral infarction via inhibition of NADPH oxidase-derived superoxide in ischemic stroke. Am J Physiol Heart Circ Physiol. 2006; 291:H2210-2215.

139. Choi DH, Kim JH, Lee KH, Kim HY, Kim YS, Choi WS, Lee J. Role of neuronal NADPH oxidase 1 in the peri-infarct regions after stroke. PLoS One. 2015; 10:e0116814.

140. Kleinschnitz C, Grund H, Wingler K, Armitage ME, Jones E, Mittal M, Barit D, Schwarz T, Geis C, Kraft P, et al. Post-stroke inhibition of induced NADPH oxidase type 4 prevents oxidative stress and neurodegeneration. PLoS Biol. 2010:8:e1000479.

141. De Silva TM, Brait VH, Drummond GR, Sobey CG, Miller AA. Nox2 oxidase activity accounts for the oxidative stress and vasomotor dysfunction in mouse cerebral arteries following ischemic stroke. PLoS One. 2011;6:e28393.

142. Ostrowski RP, Colohan AR, Zhang JH. Neuroprotective effect of hyperbaric oxygen in a rat model of subarachnoid hemorrhage. Acta Neurochir Suppl. 2006:96:188-93.

143. Ostrowski RP, Tang J, Zhang JH. Hyperbaric oxygen suppresses NADPH oxidase in a rat subarachnoid hemorrhage model. Stroke. 2006;37:1314-8.

144. Shin HK, Lee JH, Kim KY, Kim CD, Lee WS, Rhim BY, Hong KW. Impairment of autoregulatory vasodilation by $\mathrm{NAD}(\mathrm{P}) \mathrm{H}$ oxidase-dependent superoxide generation during acute stage of subarachnoid hemorrhage in rat pial artery. J Cereb Blood Flow Metab. 2002;22:869-77.

145. Kim DE, Suh YS, Lee MS, Kim KY, Lee JH, Lee HS, Hong KW, Kim CD. Vascular $\mathrm{NAD}(\mathrm{P}) \mathrm{H}$ oxidase triggers delayed cerebral vasospasm after subarachnoid hemorrhage in rats. Stroke. 2002;33:2687-91

146. Yang B, Wang S, Yu S, Chen Y, Li L, Zhang H, Zhao Y. C1q/tumor necrosis factor-related protein 3 inhibits oxidative stress during intracerebral hemorrhage via PKA signaling. Brain Res. 2016;1657:176-84.

147. Feng L, Chen Y, Ding R, Fu Z, Yang S, Deng X, Zeng J. P2X7R blockade prevents NLRP3 inflammasome activation and brain injury in a rat model of intracerebral hemorrhage: involvement of peroxynitrite. J Neuroinflammation. 2015;12:190.

148. Zhou Y, Zhao YC. Association between the nicotinamide adenine dinucleotide phosphate oxidase p22phox gene-A930G polymorphism and intracerebral hemorrhage. Mol Med Rep. 2015;11:3511-6.

149. Raz L, Zhang QG, Han D, Dong Y, De Sevilla L, Brann DW. Acetylation of the pro-apoptotic factor, p53 in the hippocampus following cerebral ischemia and modulation by estrogen. PLoS One. 2011;6:e27039.

150. Heumüller S, Wind S, Barbosa-Sicard E, Schmidt HHHW, Busse R, Schröder K, Brandes RP. Apocynin is not an inhibitor of vascular NADPH oxidases but an antioxidant. Hypertension. 2008:51:211-7.

151. Jackman KA, Miller AA, De Silva TM, Crack PJ, Drummond GR, Sobey CG. Reduction of cerebral infarct volume by apocynin requires pretreatment and is absent in Nox2-deficient mice. Br J Pharmacol. 2009;156:680-8.

152. Genovese T, Mazzon E, Paterniti I, Esposito E, Bramanti P, Cuzzocrea S. Modulation of NADPH oxidase activation in cerebral ischemia/reperfusion injury in rats. Brain Res. 2011;1372:92-102.

153. Tang XN, Zheng Z, Giffard RG, Yenari MA. Significance of marrow-derived nicotinamide adenine dinucleotide phosphate oxidase in experimental ischemic stroke. Ann Neurol. 2011;70:606-15.

154. Murotomi K, Takagi N, Takeo S, Tanonaka K. NADPH oxidase-mediated oxidative damage to proteins in the postsynaptic density after transient cerebral ischemia and reperfusion. Mol Cell Neurosci. 2011;46:681-8.

155. Tang XN, Cairns B, Cairns N, Yenari MA. Apocynin improves outcome in experimental stroke with a narrow dose range. Neuroscience. 2008;154:556-62.

156. Tang LL, Ye K, Yang XF, Zheng JS. Apocynin attenuates cerebral infarction after transient focal ischaemia in rats. J Int Med Res. 2007:35:517-22.

157. Chen H, Kim GS, Okami N, Narasimhan P, Chan PH. NADPH oxidase is involved in post-ischemic brain inflammation. Neurobiol Dis. 2011;42:341-8.

158. Kahles T, Luedike P, Endres M, Galla HJ, Steinmetz H, Busse R, NeumannHaefelin T, Brandes RP. NADPH oxidase plays a central role in blood-brain barrier damage in experimental stroke. Stroke. 2007;38:3000-6.
159. Kunz A, Anrather J, Zhou P, Orio M, ladecola C. Cyclooxygenase-2 does not contribute to postischemic production of reactive oxygen species. J Cereb Blood Flow Metab. 2007;27:545-51.

160. Walder CE, Green SP, Darbonne WC, Mathias J, Rae J, Dinauer MC, Curnutte $J T$, Thomas GR. Ischemic stroke injury is reduced in mice lacking a functional NADPH oxidase. Stroke. 1997;28:2252-8.

161. Kim HA, Brait VH, Lee S, De Silva TM, Diep H, Eisenhardt A, Drummond GR, Sobey CG. Brain infarct volume after permanent focal ischemia is not dependent on Nox2 expression. Brain Res. 2012;1483:105-11.

162. Meldrum B, Garthwaite J. Excitatory amino acid neurotoxicity and neurodegenerative disease. Trends Pharmacol Sci. 1990;11:379-87.

163. Nishizawa Y. Glutamate release and neuronal damage in ischemia. Life Sci. 2001:69:369-81.

164. Meldrum BS. The role of glutamate in epilepsy and other CNS disorders. Neurology. 1994;44:S14-23.

165. Wang Z, Wei X, Liu K, Zhang X, Yang F, Zhang H, He Y, Zhu T, Li F, Shi W, et al. NOX2 deficiency ameliorates cerebral injury through reduction of complexin II-mediated glutamate excitotoxicity in experimental stroke. Free Radic Biol Med. 2013;65:942-51.

166. Hur J, Lee P, Kim MJ, Kim Y, Cho YW. Ischemia-activated microglia induces neuronal injury via activation of gp91phox NADPH oxidase. Biochem Biophys Res Commun. 2010;391:1526-30.

167. Nishimura A, Ago T, Kuroda J, Arimura K, Tachibana M, Nakamura K, Wakisaka Y, Sadoshima J, lihara K, Kitazono T. Detrimental role of pericyte Nox4 in the acute phase of brain ischemia. J Cereb Blood Flow Metab. 2015;36:1143-54.

168. Liu Z, Tuo YH, Chen JW, Wang QY, Li S, Li MC, Dai G, Wang JS, Zhang YL, Feng L, Shi ZS. NADPH oxidase inhibitor regulates microRNAs with improved outcome after mechanical reperfusion. J Neurointerv Surg. 2016.

169. Tuo YH, Liu Z, Chen JW, Wang QY, Li SL, Li MC, Dai G, Wang JS, Zhang YL, Feng $L$, Shi ZS. NADPH oxidase inhibitor improves outcome of mechanical reperfusion by suppressing hemorrhagic transformation. J Neurointerv Surg. 2016.

170. Titova E, Ostrowski RP, Sowers LC, Zhang JH, Tang J. Effects of apocynin and ethanol on intracerebral haemorrhage-induced brain injury in rats. Clin Exp Pharmacol Physiol. 2007:34:845-50.

171. Tang J, Liu J, Zhou C, Ostanin D, Grisham MB, Neil Granger D, Zhang JH. Role of NADPH oxidase in the brain injury of intracerebral hemorrhage. J Neurochem. 2005;94:1342-50.

172. Liu S, Tang J, Ostrowski RP, Titova E, Monroe C, Chen W, Lo W, Martin R, Zhang $\mathrm{JH}$. Oxidative stress after subarachnoid hemorrhage in gp91phox knockout mice. Can J Neurol Sci. 2007;34:356-61.

173. Rosenfeld JV, Maas Al, Bragge P, Morganti-Kossmann MC, Manley GT, Gruen RL. Early management of severe traumatic brain injury. Lancet. 2012;380:1088-98.

174. Finfer SR, Cohen J. Severe traumatic brain injury. Resuscitation. 2001;48:77-90.

175. Loane DJ, Kumar A, Stoica BA, Cabatbat R, Faden Al. Progressive neurodegeneration after experimental brain trauma: association with chronic microglial activation. J Neuropathol Exp Neurol. 2014;73:14-29.

176. Maas AIR, Stocchetti N, Bullock R. Moderate and severe traumatic brain injury in adults. Lancet Neurol. 2008;7:728-41.

177. Niesman IR, Schilling JM, Shapiro LA, Kellerhals SE, Bonds JA, Kleschevnikov AM, Cui W, Voong A, Krajewski S, Ali SS, et al. Traumatic brain injury enhances neuroinflammation and lesion volume in caveolin deficient mice. J Neuroinflammation. 2014;11:39.

178. Tajiri N, Kellogg SL, Shimizu T, Arendash GW, Borlongan CV. Traumatic brain injury precipitates cognitive impairment and extracellular Abeta aggregation in Alzheimer's disease transgenic mice. PLoS One. 2013;8:e78851.

179. Giunta B, Obregon D, Velisetty R, Sanberg PR, Borlongan CV, Tan J. The immunology of traumatic brain injury: a prime target for Alzheimer's disease prevention. J Neuroinflammation. 2012;9:185

180. Carbonell WS, Grady MS. Regional and temporal characterization of neuronal, glial, and axonal response after traumatic brain injury in the mouse. Acta Neuropathol. 1999;98:396-406.

181. Abdul-Muneer PM, Schuetz H, Wang F, Skotak M, Jones J, Gorantla S, Zimmerman MC, Chandra N, Haorah J. Induction of oxidative and nitrosative damage leads to cerebrovascular inflammation in an animal model of mild traumatic brain injury induced by primary blast. Free Radic Biol Med. 2013;60:282-91.

182. Unterberg AW, Stroop R, Thomale UW, Kiening KL, Pauser S, Vollmann W. Characterisation of brain edema following "controlled cortical impact injury" in rats. Acta Neurochir Suppl. 1997;70:106-8. 
183. Abdul-Muneer PM, Chandra N, Haorah J. Interactions of oxidative stress and neurovascular inflammation in the pathogenesis of traumatic brain injury. Mol Neurobiol. 2014:51:966-79.

184. Lu X-Y, Wang H-D, Xu J-G, Ding K, Li T. NADPH oxidase inhibition improves neurological outcome in experimental traumatic brain injury. Neurochem Int. 2014;69:14-9.

185. Dohi K, Ohtaki H, Nakamachi T, Yofu S, Satoh K, Miyamoto K, Song D, Tsunawaki S, Shioda S, Aruga T. Gp91phox (NOX2) in classically activated microglia exacerbates traumatic brain injury. J Neuroinflammation. 2010;7:41.

186. Kumar A, Alvarez-Croda DM, Stoica BA, Faden Al, Loane DJ. Microglial/ Macrophage Polarization Dynamics following Traumatic Brain Injury. J Neurotrauma. 2015: [Epub ahead of print].

187. Lucke-Wold BP, Naser ZJ, Logsdon AF, Turner RC, Smith KE, Robson MJ, Bailes JE, Lee JM, Rosen CL, Huber JD. Amelioration of nicotinamide adenine dinucleotide phosphate-oxidase mediated stress reduces cell death after blast-induced traumatic brain injury. Transl Res. 2015;166:509-28. e501.

188. Li Z, Tian F, Shao Z, Shen X, Qi X, Li H, Wang Z, Chen G. Expression and clinical significance of non-phagocytic cell oxidase 2 and 4 after human traumatic brain injury. Neurol Sci. 2014;36:61-71.

189. Liao Y, Liu P, Guo F, Zhang Z-Y, Zhang Z. Oxidative burst of circulating neutrophils following traumatic brain injury in human. PLoS One. 2013;8:e68963.

190. Choi BY, Jang BG, Kim JH, Lee BE, Sohn M, Song HK, Suh SW. Prevention of traumatic brain injury-induced neuronal death by inhibition of NADPH oxidase activation. Brain Res. 2012;1481:49-58.

191. Ferreira APO, Rodrigues FS, Della-Pace ID, Mota BC, Oliveira SM, Velho Gewehr CC, Bobinski F, de Oliveira CV, Brum JS, Oliveira MS, et al. The effect of NADPH-oxidase inhibitor apocynin on cognitive impairment induced by moderate lateral fluid percussion injury: role of inflammatory and oxidative brain damage. Neurochem Int. 2013;63:583-93.

192. Bennett DA, Schneider JA, Buchman AS, Barnes LL, Boyle PA, Wilson RS. Overview and findings from the rush memory and aging project. Curr Alzheimer Res. 2012;9:646-63.

193. Kim HA, Miller AA, Drummond GR, Thrift AG, Arumugam TV, Phan TG, Srikanth VK, Sobey CG. Vascular cognitive impairment and Alzheimer's disease: role of cerebral hypoperfusion and oxidative stress. Naunyn Schmiedebergs Arch Pharmacol. 2012;385:953-9.

194. Mu Y, Gage FH. Adult hippocampal neurogenesis and its role in Alzheimer's disease. Mol Neurodegener. 2011;6:85.

195. Park KW, Baik HH, Jin BK. IL-13-induced oxidative stress via microglial NADPH oxidase contributes to death of hippocampal neurons in vivo. J Immunol. 2009;183:4666-74.

196. Shimohama S, Tanino H, Kawakami N, Okamura N, Kodama H, Yamaguchi T, Hayakawa T, Nunomura A, Chiba S, Perry G, et al. Activation of NADPH oxidase in Alzheimer's disease brains. Biochem Biophys Res Commun. 2000;273:5-9.

197. Ansari MA, Scheff SW. NADPH-oxidase activation and cognition in Alzheimer disease progression. Free Radic Biol Med. 2011;51:171-8.

198. Carrano A, Hoozemans JJ, van der Vies SM, Rozemuller AJ, van Horssen J, de Vries HE. Amyloid Beta induces oxidative stress-mediated blood-brain barrier changes in capillary amyloid angiopathy. Antioxid Redox Signal. 2011;15:1167-78.

199. Carrano A, Hoozemans JJ, van der Vies SM, van Horssen J, de Vries HE, Rozemuller AJ. Neuroinflammation and blood-brain barrier changes in capillary amyloid angiopathy. Neurodegener Dis. 2012;10:329-31.

200. Bruce-Keller AJ, Gupta S, Knight AG, Beckett TL, McMullen JM, Davis PR, Murphy MP, Van Eldik LJ, St Clair D, Keller JN. Cognitive impairment in humanized APPXPS1 mice is linked to Abeta(1-42) and NOX activation. Neurobiol Dis. 2011:44:317-26.

201. de la Monte SM, Wands JR. Molecular indices of oxidative stress and mitochondrial dysfunction occur early and often progress with severity of Alzheimer's disease. J Alzheimers Dis. 2006;9:167-81.

202. Choi DH, Lee KH, Kim JH, Seo JH, Kim HY, Shin CY, Han JS, Han SH, Kim YS, Lee J. NADPH oxidase 1, a novel molecular source of ROS in Hippocampal neuronal death in vascular dementia. Antioxid Redox Signal. 2014:21:533-50.

203. Han BH, Zhou ML, Johnson AW, Singh I, Liao F, Vellimana AK, Nelson JW, Milner E, Cirrito JR, Basak J, et al. Contribution of reactive oxygen species to cerebral amyloid angiopathy, vasomotor dysfunction, and microhemorrhage in aged Tg2576 mice. Proc Natl Acad Sci U S A. 2015;112:E881-890.

204. Park L, Anrather J, Zhou P, Frys K, Pitstick R, Younkin S, Carlson GA, ladecola C. NADPH-oxidase-derived reactive oxygen species mediate the cerebrovascular dysfunction induced by the amyloid beta peptide. J Neurosci. 2005;25:1769-77.
205. Choi SH, Aid S, Kim HW, Jackson SH, Bosetti F. Inhibition of NADPH oxidase promotes alternative and anti-inflammatory microglial activation during neuroinflammation. J Neurochem. 2012;120:292-301.

206. Brichta L, Greengard P, Flajolet M. Advances in the pharmacological treatment of Parkinson's disease: targeting neurotransmitter systems. Trends Neurosci. 2013;36:543-54.

207. Rodriguez-Oroz MC, Jahanshahi M, Krack P, Litvan I, Macias R, Bezard E, Obeso JA. Initial clinical manifestations of Parkinson's disease: features and pathophysiological mechanisms. Lancet Neurol. 2009;8:1128-39.

208. Blesa J, Trigo-Damas I, Quiroga-Varela A, Jackson-Lewis VR. Oxidative stress and Parkinson's disease. Front Neuroanat. 2015;9:91.

209. Przedborski S, Ischiropoulos H. Reactive oxygen and nitrogen species: weapons of neuronal destruction in models of Parkinson's disease. Antioxid Redox Signal. 2005;7:685-93.

210. Alam ZI, Daniel SE, Lees AJ, Marsden DC, Jenner P, Halliwell B. A generalised increase in protein carbonyls in the brain in Parkinson's but not incidental Lewy body disease. J Neurochem. 1997;69:1326-9.

211. Chen H, Zhang SM, Hernán MA, Schwarzschild MA, Willett WC, Colditz GA, Speizer FE, Ascherio A. Nonsteroidal anti-inflammatory drugs and the risk of Parkinson disease. Arch Neurol. 2003;60:1059-64.

212. Hirsch EC, Hunot S, Damier P, Faucheux B. Glial cells and inflammation in Parkinson's disease: a role in neurodegeneration? Ann Neurol. 1998;44:S115-120.

213. Cicchetti F, Brownell AL, Williams K, Chen YI, Livni E, Isacson O. Neuroinflammation of the nigrostriatal pathway during progressive 6-OHDA dopamine degeneration in rats monitored by immunohistochemistry and PET imaging. Eur J Neurosci. 2002;15:991-8.

214. Langston JW, Forno LS, Tetrud J, Reeves AG, Kaplan JA, Karluk D. Evidence of active nerve cell degeneration in the substantia nigra of humans years after 1-methyl-4-phenyl-1,2,3,6-tetrahydropyridine exposure. Ann Neurol. 1999;46:598-605.

215. Gao H-M, Liu B, Zhang W, Hong J-S. Critical role of microglial NADPH oxidase-derived free radicals in the in vitro MPTP model of Parkinson's disease. FASEB J. 2003;17:1954-6.

216. Choi D-H, Cristóvão AC, Guhathakurta S, Lee J, Joh TH, Beal MF, Kim Y-S. NADPH oxidase 1-mediated oxidative stress leads to dopamine neuron death in Parkinson's disease. Antioxid Redox Signal. 2012;16:1033-45.

217. Hernandes MS, Santos GDR, Café-Mendes CC, Lima LS, Scavone C, Munhoz $C D$, Britto LRG. Microglial cells are involved in the susceptibility of NADPH oxidase knockout mice to 6-hydroxy-dopamine-induced neurodegeneration. PLoS One. 2013:8:e75532.

218. Wu D-C, Teismann P, Tieu K, Vila M, Jackson-Lewis V, Ischiropoulos H, Przedborski S. NADPH oxidase mediates oxidative stress in the 1-methyl4-phenyl-1,2,3,6-tetrahydropyridine model of Parkinson's disease. Proc Natl Acad Sci U S A. 2003;100:6145-50.

219. Sharma N, Nehru B. Apocyanin, a microglial NADPH oxidase inhibitor prevents dopaminergic neuronal degeneration in lipopolysaccharide-induced Parkinson's disease model. Mol Neurobiol. 2015:53:3326-37.

220. Jiang T, Hoekstra J, Heng X, Kang W, Ding J, Liu J, Chen S, Zhang J. P2X7 receptor is critical in alpha-synuclein-mediated microglial NADPH oxidase activation. Neurobiol Aging. 2015;36:2304-18.

221. Wang Q, Chu CH, Qian L, Chen SH, Wilson B, Oyarzabal E, Jiang L, Ali S, Robinson B, Kim HC, Hong JS. Substance P exacerbates dopaminergic neurodegeneration through neurokinin-1 receptor-independent activation of microglial NADPH oxidase. J Neurosci. 2014;34:12490-503.

222. Amatullah H, Shan Y, Beauchamp BL, Gali PL, Gupta S, Maron-Gutierrez T, Speck ER, Fox-Robichaud AE, Tsang JL, Mei SH, et al. DJ-1/PARK7 Impairs Bacterial Clearance in Sepsis. Am J Respir Crit Care Med. 2016.

223. Liu W, Wu H, Chen L, Wen Y, Kong X, Gao WQ. Park7 interacts with p47(phox) to direct NADPH oxidase-dependent ROS production and protect against sepsis. Cell Res. 2015;25:691-706.

224. Cuevas S, Zhang Y, Yang Y, Escano C, Asico L, Jones JE, Armando I, Jose PA. Role of renal DJ-1 in the pathogenesis of hypertension associated with increased reactive oxygen species production. Hypertension. 2012; 59:446-52.

225. Gandhi S, Wood-Kaczmar A, Yao Z, Plun-Favreau H, Deas E, Klupsch K, Downward J, Latchman DS, Tabrizi SJ, Wood NW, et al. PINK1-associated Parkinson's disease is caused by neuronal vulnerability to calcium-induced cell death. Mol Cell. 2009;33:627-38.

226. Cristóvão AC, Guhathakurta S, Bok E, Je G, Yoo SD, Choi DH, Kim YS. NADPH oxidase 1 mediates alpha-synucleinopathy in Parkinson's disease. J Neurosci. 2012;32:14465-77 
227. Hernandes MS, Café-Mendes CC, Britto LRG. NADPH oxidase and the degeneration of dopaminergic neurons in parkinsonian mice. Oxid Med Cell Longev. 2013;2013:157857.

228. Gao HM, Liu B, Hong JS. Critical role for microglial NADPH oxidase in rotenone-induced degeneration of dopaminergic neurons. J Neurosci. 2003; 23:6181-7.

229. Dranka BP, Gifford A, Ghosh A, Zielonka J, Joseph J, Kanthasamy AG, Kalyanaraman B. Diapocynin prevents early Parkinson's disease symptoms in the leucine-rich repeat kinase $2\left(\operatorname{LRRK} 2 R^{1441} \mathrm{G}\right)$ transgenic mouse. Neurosci Lett. 2013;549:57-62

230. Ghosh A, Kanthasamy A, Joseph J, Anantharam V, Srivastava P, Dranka BP, Kalyanaraman B, Kanthasamy AG. Anti-inflammatory and neuroprotective effects of an orally active apocynin derivative in pre-clinical models of Parkinson's disease. J Neuroinflammation. 2012;9:241.

231. Philippens $\mid H$, Wubben JA, Finsen B, 't Hart BA. Oral treatment with the NADPH oxidase antagonist apocynin mitigates clinical and pathological features of parkinsonism in the MPTP marmoset model. J Neuroimmune Pharmacol. 2013;8:715-26.

232. Lindvall O, Kokaia Z. Neurogenesis following stroke affecting the adult brain. Cold Spring Harb Perspect Biol. 2015;7:a019034.

233. Dash PK, Mach SA, Moore AN. Enhanced neurogenesis in the rodent hippocampus following traumatic brain injury. J Neurosci Res. 2001;63:313-9.

234. Yu TS, Zhang G, Liebl DJ, Kernie SG. Traumatic brain injury-induced hippocampal neurogenesis requires activation of early nestin-expressing progenitors. J Neurosci. 2008;28:12901-12.

235. Jin K, Peel AL, Mao XO, Xie L, Cottrell BA, Henshall DC, Greenberg DA. Increased hippocampal neurogenesis in Alzheimer's disease. Proc Natl Acad Sci U S A. 2004;101:343-7.

236. Yu Y, He J, Zhang Y, Luo H, Zhu S, Yang Y, Zhao T, Wu J, Huang Y, Kong J, et al. Increased hippocampal neurogenesis in the progressive stage of Alzheimer's disease phenotype in an APP/PS1 double transgenic mouse model. Hippocampus. 2009:19:1247-53.

237. Cummings BJ, Uchida N, Tamaki SJ, Salazar DL, Hooshmand M, Summers R, Gage FH, Anderson AJ. Human neural stem cells differentiate and promote locomotor recovery in spinal cord-injured mice. Proc Natl Acad Sci U S A. 2005:102:14069-74.

238. Haus DL, Lopez-Velazquez L, Gold EM, Cunningham KM, Perez H, Anderson AJ, Cummings BJ. Transplantation of human neural stem cells restores cognition in an immunodeficient rodent model of traumatic brain injury. Exp Neurol. 2016;281:1-16.

239. Chen L, Qiu R, Li L, He D, Lv H, Wu X, Gu N. The role of exogenous neural stem cells transplantation in cerebral ischemic stroke. J Biomed Nanotechnol. 2014;10:3219-30.

240. Ibrahim S, Hu W, Wang X, Gao X, He C, Chen J. Traumatic brain injury causes aberrant migration of adult-born neurons in the hippocampus. Sci Rep. 2016;6:21793.

241. Kokovay $E$, Wang $Y$, Kusek $G$, Wurster R, Lederman $P$, Lowry N, Shen $Q$, Temple S. VCAM1 is essential to maintain the structure of the SVZ niche and acts as an environmental sensor to regulate SVZ lineage progression. Cell Stem Cell. 2012;11:220-30.

242. Le Belle JE, Orozco NM, Paucar AA, Saxe JP, Mottahedeh J, Pyle AD, Wu H, Kornblum HI. Proliferative neural stem cells have high endogenous ROS levels that regulate self-renewal and neurogenesis in a PI3K/Akt-dependant manner. Cell Stem Cell. 2011;8:59-71.

243. Ager RR, Davis JL, Agazaryan A, Benavente F, Poon WW, LaFerla FM, BlurtonJones M. Human neural stem cells improve cognition and promote synaptic growth in two complementary transgenic models of Alzheimer's disease and neuronal loss. Hippocampus. 2015;25:813-26.

244. Dickinson BC, Peltier J, Stone D, Schaffer DV, Chang CJ. Nox2 redox signaling maintains essential cell populations in the brain. Nat Chem Biol. 2011;7:106-12.

245. Yoneyama M, Kawada K, Gotoh Y, Shiba T, Ogita K. Endogenous reactive oxygen species are essential for proliferation of neural stem/progenitor cells. Neurochem Int. 2010:56:740-6.

246. Valencia A, Sapp E, Kimm JS, McClory H, Reeves PB, Alexander J, Ansong KA, Masso N, Frosch MP, Kegel KB, et al. Elevated NADPH oxidase activity contributes to oxidative stress and cell death in Huntington's disease. Hum Mol Genet. 2013;22:1112-31.

247. Barnabe-Heider F, Goritz C, Sabelstrom H, Takebayashi H, Pfrieger FW, Meletis K, Frisen J. Origin of new glial cells in intact and injured adult spinal cord. Cell Stem Cell. 2010;7:470-82.
248. Schulz JB, Henshaw DR, MacGarvey U, Beal MF. Involvement of oxidative stress in 3-nitropropionic acid neurotoxicity. Neurochem Int. 1996;29:167-71.

249. Rey FE, Cifuentes ME, Kiarash A, Quinn MT, Pagano PJ. Novel competitive inhibitor of $\mathrm{NAD}(\mathrm{P}) \mathrm{H}$ oxidase assembly attenuates vascular $\mathrm{O}(2)(-)$ and systolic blood pressure in mice. Circ Res. 2001;89:408-14.

250. Wijesekera LC, Leigh PN. Amyotrophic lateral sclerosis. Orphanet J Rare Dis. 2009;4:3.

251. Mancuso R, Navarro X. Amyotrophic lateral sclerosis: Current perspectives from basic research to the clinic. Prog Neurobiol. 2015;133:1-26.

252. Miller RG, Mitchell JD, Lyon M, Moore DH. Riluzole for amyotrophic lateral sclerosis (ALS)/motor neuron disease (MND). Amyotroph Lateral Scler Other Motor Neuron Disord. 2003:4:191-206.

253. Carter BJ, Anklesaria P, Choi S, Engelhardt JF. Redox modifier genes and pathways in amyotrophic lateral sclerosis. Antioxid Redox Signal. 2009;11:1569-86.

254. Barber SC, Shaw PJ. Oxidative stress in ALS: key role in motor neuron injury and therapeutic target. Free Radic Biol Med. 2010;48:629-41.

255. Shaw PJ, Ince PG, Falkous G, Mantle D. Oxidative damage to protein in sporadic motor neuron disease spinal cord. Ann Neurol. 1995;38:691-5.

256. Abe K, Pan LH, Watanabe M, Kato T, Itoyama Y. Induction of nitrotyrosinelike immunoreactivity in the lower motor neuron of amyotrophic lateral sclerosis. Neurosci Lett. 1995:199:152-4.

257. Shibata N, Nagai R, Uchida K, Horiuchi S, Yamada S, Hirano A, Kawaguchi M, Yamamoto T, Sasaki S, Kobayashi M. Morphological evidence for lipid peroxidation and protein glycoxidation in spinal cords from sporadic amyotrophic lateral sclerosis patients. Brain Res. 2001:917:97-104.

258. Chang Y, Kong Q, Shan X, Tian G, llieva H, Cleveland DW, Rothstein JD, Borchelt DR, Wong PC, Lin CL. Messenger RNA oxidation occurs early in disease pathogenesis and promotes motor neuron degeneration in ALS PLoS One. 2008;3:e2849.

259. Ferrante RJ, Browne SE, Shinobu LA, Bowling AC, Baik MJ, MacGarvey U, Kowall NW, Brown Jr RH, Beal MF. Evidence of increased oxidative damage in both sporadic and familial amyotrophic lateral sclerosis. J Neurochem. 1997;69:2064-74.

260. Smith RG, Henry YK, Mattson MP, Appel SH. Presence of 4-hydroxynonenal in cerebrospinal fluid of patients with sporadic amyotrophic lateral sclerosis. Ann Neurol. 1998:44:696-9.

261. Ryberg H, Soderling AS, Davidsson P, Blennow K, Caidahl K, Persson LI. Cerebrospinal fluid levels of free 3-nitrotyrosine are not elevated in the majority of patients with amyotrophic lateral sclerosis or Alzheimer's disease. Neurochem Int. 2004:45:57-62.

262. Wu DC, Re DB, Nagai M, Ischiropoulos H, Przedborski S. The inflammatory NADPH oxidase enzyme modulates motor neuron degeneration in amyotrophic lateral sclerosis mice. Proc Natl Acad Sci U S A. 2006;103:12132-7.

263. Rosen DR, Siddique T, Patterson D, Figlewicz DA, Sapp P, Hentati A, Donaldson D, Goto J, O'Regan JP, Deng HX, et al. Mutations in Cu/Zn superoxide dismutase gene are associated with familial amyotrophic lateral sclerosis. Nature. 1993;362:59-62.

264. Harraz MM, Marden JJ, Zhou W, Zhang Y, Williams A, Sharov VS, Nelson K, Luo M, Paulson H, Schoneich C, Engelhardt JF. SOD1 mutations disrupt redox-sensitive Rac regulation of NADPH oxidase in a familial ALS model. J Clin Invest. 2008;118:659-70.

265. Boillee S, Cleveland DW. Revisiting oxidative damage in ALS: microglia, Nox, and mutant SOD1. J Clin Invest. 2008:118:474-8.

266. Marchetto MC, Muotri AR, Mu Y, Smith AM, Cezar GG, Gage FH. Non-cellautonomous effect of human SOD1 G37R astrocytes on motor neurons derived from human embryonic stem cells. Cell Stem Cell. 2008;3:649-57.

267. Dunckley T, Huentelman MJ, Craig DW, Pearson JV, Szelinger S, Joshipura K, Halperin RF, Stamper C, Jensen KR, Letizia D, et al. Whole-genome analysis of sporadic amyotrophic lateral sclerosis. N Engl J Med. 2007;357:775-88.

268. Desnuelle C, Dib M, Garrel C, Favier A. A double-blind, placebo-controlled randomized clinical trial of alpha-tocopherol (vitamin E) in the treatment of amyotrophic lateral sclerosis. ALS riluzole-tocopherol Study Group. Amyotroph Lateral Scler Other Motor Neuron Disord. 2001;2:9-18.

269. Galbussera A, Tremolizzo L, Brighina L, Testa D, Lovati R, Ferrarese C, Cavaletti G, Filippini G. Vitamin E intake and quality of life in amyotrophic lateral sclerosis patients: a follow-up case series study. Neurol Sci. 2006;27:190-3.

270. Graf M, Ecker D, Horowski R, Kramer B, Riederer P, Gerlach M, Hager C, Ludolph AC, Becker G, Osterhage J, et al. High dose vitamin E therapy in amyotrophic lateral sclerosis as add-on therapy to riluzole: results of a placebo-controlled double-blind study. J Neural Transm (Vienna). 2005;112:649-60. 
271. Ferrante KL, Shefner J, Zhang H, Betensky R, O'Brien M, Yu H, Fantasia M, Taft J, Beal MF, Traynor B, et al. Tolerance of high-dose (3,000 mg/day) coenzyme Q10 in ALS. Neurology. 2005;65:1834-6.

272. Kaufmann P, Thompson JL, Levy G, Buchsbaum R, Shefner J, Krivickas LS, Katz J, Rollins Y, Barohn RJ, Jackson CE, et al. Phase II trial of CoQ10 for ALS finds insufficient evidence to justify phase III. Ann Neurol. 2009;66:235-44.

273. Yoshino H, Kimura A. Investigation of the therapeutic effects of edaravone, a free radical scavenger, on amyotrophic lateral sclerosis (Phase II study). Amyotroph Lateral Scler. 2006;7:241-5.

274. Ito H, Wate R, Zhang J, Ohnishi S, Kaneko S, Ito H, Nakano S, Kusaka H. Treatment with edaravone, initiated at symptom onset, slows motor decline and decreases SOD1 deposition in ALS mice. Exp Neurol. 2008;213:448-55.

275. Marrali G, Casale F, Salamone P, Fuda G, Caorsi C, Amoroso A, Brunetti M, Restagno G, Barberis M, Bertuzzo D, et al. NADPH oxidase (NOX2) activity is a modifier of survival in ALS. J Neurol. 2014;261:2178-83.

276. Marden JJ, Harraz MM, Williams AJ, Nelson K, Luo M, Paulson H, Engelhardt JF. Redox modifier genes in amyotrophic lateral sclerosis in mice. J Clin Invest. 2007;117:2913-9.

277. Trumbull KA, McAllister D, Gandelman MM, Fung WY, Lew T, Brennan L, Lopez N, Morre J, Kalyanaraman B, Beckman JS. Diapocynin and apocynin administration fails to significantly extend survival in G93A SOD1 ALS mice. Neurobiol Dis. 2012;45:137-44.

278. Chaudhuri A. Multiple sclerosis is primarily a neurodegenerative disease. J Neural Transm (Vienna). 2013;120:1463-6.

279. Friese MA, Schattling B, Fugger L. Mechanisms of neurodegeneration and axonal dysfunction in multiple sclerosis. Nat Rev Neurol. 2014;10:225-38.

280. Noseworthy JH, Lucchinetti C, Rodriguez M, Weinshenker BG. Multiple sclerosis. N Engl J Med. 2000;343:938-52.

281. Lassmann $H$, van Horssen J. The molecular basis of neurodegeneration in multiple sclerosis. FEBS Lett. 2011;585:3715-23.

282. Trapp BD, Nave KA. Multiple sclerosis: an immune or neurodegenerative disorder? Annu Rev Neurosci. 2008;31:247-69.

283. Pittock SJ, Lucchinetti CF. The pathology of MS: new insights and potential clinical applications. Neurologist. 2007;13:45-56.

284. Haider L, Fischer MT, Frischer JM, Bauer J, Hoftberger R, Botond G, Esterbauer H, Binder CJ, Witztum JL, Lassmann H. Oxidative damage in multiple sclerosis lesions. Brain. 2011;134:1914-24.

285. Arnold P, Mojumder D, Detoledo J, Lucius R, Wilms H. Pathophysiological processes in multiple sclerosis: focus on nuclear factor erythroid-2-related factor two and emerging pathways. Clin Pharmacol. 2014;6:35-42.

286. van Horssen J, Witte ME, Schreibelt G, de Vries HE. Radical changes in multiple sclerosis pathogenesis. Biochim Biophys Acta. 1812;2011:141-50.

287. Smith KJ, Kapoor R, Felts PA. Demyelination: the role of reactive oxygen and nitrogen species. Brain Pathol. 1999:9:69-92.

288. Bizzozero OA, DeJesus G, Callahan K, Pastuszyn A. Elevated protein carbonylation in the brain white matter and gray matter of patients with multiple sclerosis. J Neurosci Res. 2005;81:687-95.

289. Cross AH, Manning PT, Keeling RM, Schmidt RE, Misko TP. Peroxynitrite formation within the central nervous system in active multiple sclerosis. J Neuroimmunol. 1998:88:45-56.

290. Qin J, Goswami R, Balabanov R, Dawson G. Oxidized phosphatidylcholine is a marker for neuroinflammation in multiple sclerosis brain. J Neurosci Res. 2007:85:977-84

291. Vladimirova O, O'Connor J, Cahill A, Alder H, Butunoi C, Kalman B. Oxidative damage to DNA in plaques of MS brains. Mult Scler. 1998;4:413-8.

292. Kemp K, Redondo J, Hares K, Rice C, Scolding N, Wilkins A. Oxidative injury in multiple sclerosis cerebellar grey matter. Brain Res. 1642;2016:452-60.

293. van Horssen J, Schreibelt G, Drexhage J, Hazes T, Dijkstra CD, van der Valk P, de Vries HE. Severe oxidative damage in multiple sclerosis lesions coincides with enhanced antioxidant enzyme expression. Free Radic Biol Med. 2008; 45:1729-37.

294. Lu F, Selak M, O'Connor J, Croul S, Lorenzana C, Butunoi C, Kalman B. Oxidative damage to mitochondrial DNA and activity of mitochondrial enzymes in chronic active lesions of multiple sclerosis. J Neurol Sci. 2000;177:95-103.

295. Li J, Baud O, Vartanian T, Volpe JJ, Rosenberg PA. Peroxynitrite generated by inducible nitric oxide synthase and NADPH oxidase mediates microglial toxicity to oligodendrocytes. Proc Natl Acad Sci U S A. 2005;102:9936-41.

296. Fischer MT, Sharma R, Lim JL, Haider L, Frischer JM, Drexhage J, Mahad D, Bradl M, van Horssen J, Lassmann H. NADPH oxidase expression in active multiple sclerosis lesions in relation to oxidative tissue damage and mitochondrial injury. Brain. 2012;135:886-99.
297. van Horssen J, Singh S, van der Pol S, Kipp M, Lim JL, Peferoen L, Gerritsen W, Kooi EJ, Witte ME, Geurts JJ, et al. Clusters of activated microglia in normal-appearing white matter show signs of innate immune activation. J Neuroinflammation. 2012;9:156

298. Mossberg N, Movitz C, Hellstrand K, Bergstrom T, Nilsson S, Andersen O. Oxygen radical production in leukocytes and disease severity in multiple sclerosis. J Neuroimmunol. 2009;213:131-4.

299. Constantinescu CS, Farooqi N, O'Brien K, Gran B. Experimental autoimmune encephalomyelitis (EAE) as a model for multiple sclerosis (MS). Br J Pharmacol. 2011;164:1079-106.

300. Schuh C, Wimmer I, Hametner S, Haider L, Van Dam AM, Liblau RS, Smith KJ Probert L, Binder CJ, Bauer J, et al. Oxidative tissue injury in multiple sclerosis is only partly reflected in experimental disease models. Acta Neuropathol. 2014;128:247-66.

301. Seo JE, Hasan M, Rahaman KA, Kang MJ, Jung BH, Kwon OS. A leading role for NADPH oxidase in an in-vitro study of experimental autoimmune encephalomyelitis. Mol Immunol. 2016;72:19-27.

302. Kandagaddala LD, Kang MJ, Haque MM, Im HY, Seo JE, Chung BC, Jung BH, Patterson TA, Kwon OS. In vitro screening of NADPH oxidase inhibitors and in vivo effects of L-leucinethiol on experimental autoimmune encephalomyelitis-induced mice. J Neurol Sci. 2012;318:36-44.

303. Kandagaddala LD, Kang MJ, Chung BC, Patterson TA, Kwon OS. Expression and activation of matrix metalloproteinase-9 and NADPH oxidase in tissues and plasma of experimental autoimmune encephalomyelitis in mice. Exp Toxicol Pathol. 2012;64:109-14.

304. Zarruk JG, Berard JL, PassosdosSantos R, Kroner A, Lee J, Arosio P, David S. Expression of iron homeostasis proteins in the spinal cord in experimental autoimmune encephalomyelitis and their implications for iron accumulation. Neurobiol Dis. 2015;81:93-107.

305. Di Filippo M, de lure A, Giampa C, Chiasserini D, Tozzi A, Orvietani PL, Ghiglieri V, Tantucci M, Durante V, Quiroga-Varela A, et al. Persistent activation of microglia and NADPH drive hippocampal dysfunction in experimental multiple sclerosis. Sci Rep. 2016;6:20926.

306. Choi BY, Kim JH, Kho AR, Kim IY, Lee SH, Lee BE, Choi E, Sohn M, Stevenson $\mathrm{M}$, Chung TN, et al. Inhibition of NADPH oxidase activation reduces EAEinduced white matter damage in mice. J Neuroinflammation. 2015;12:104.

307. van der Goes A, Brouwer J, Hoekstra K, Roos D, van den Berg TK, Dijkstra $C D$. Reactive oxygen species are required for the phagocytosis of myelin by macrophages. J Neuroimmunol. 1998;92:67-75.

308. Liu Y, Hao W, Letiembre M, Walter S, Kulanga M, Neumann H, Fassbender K. Suppression of microglial inflammatory activity by myelin phagocytosis: role of p47-PHOX-mediated generation of reactive oxygen species. J Neurosci. 2006:26:12904-13.

309. van der Veen RC, Dietlin TA, Hofman FM, Pen L, Segal BH, Holland SM. Superoxide prevents nitric oxide-mediated suppression of helper $\mathrm{T}$ lymphocytes: decreased autoimmune encephalomyelitis in nicotinamide adenine dinucleotide phosphate oxidase knockout mice. J Immunol. 2000;164:5177-83.

310. Hultqvist M, Olofsson P, Holmberg J, Backstrom BT, Tordsson J, Holmdahl R. Enhanced autoimmunity, arthritis, and encephalomyelitis in mice with a reduced oxidative burst due to a mutation in the Ncf1 gene. Proc Natl Acad Sci U S A. 2004;101:12646-51.

311. Li S, Vana AC, Ribeiro R, Zhang Y. Distinct role of nitric oxide and peroxynitrite in mediating oligodendrocyte toxicity in culture and in experimental autoimmune encephalomyelitis. Neuroscience. 2011;184:107-19.

312. Green AR, Ashwood T. Free radical trapping as a therapeutic approach to neuroprotection in stroke: experimental and clinical studies with NXY-059 and free radical scavengers. Curr Drug Targets CNS Neurol Disord. 2005;4:109-18.

313. Danta CC, Piplani P. The discovery and development of new potential antioxidant agents for the treatment of neurodegenerative diseases. Expert Opin Drug Discov. 2014;9:1205-22.

314. Altenhöfer S, Radermacher KA, Kleikers PWM, Wingler K, Schmidt HHHW. Evolution of NADPH oxidase inhibitors: selectivity and mechanisms for target engagement. Antioxid Redox Signal. 2014;23:406-27.

315. Barbieri SS, Cavalca V, Eligini S, Brambilla M, Caiani A, Tremoli E, Colli S. Apocynin prevents cyclooxygenase 2 expression in human monocytes through NADPH oxidase and glutathione redox-dependent mechanisms. Free Radic Biol Med. 2004;37:156-65.

316. Johnson DK, Schillinger KJ, Kwait DM, Hughes CV, McNamara EJ, Ishmael F, O'Donnell RW, Chang M-M, Hogg MG, Dordick JS, et al. Inhibition of NADPH oxidase activation in endothelial cells by ortho-methoxy-substituted catechols. Endothelium. 2002;9:191-203. 
317. Peters EA, Hiltermann JT, Stolk J. Effect of apocynin on ozone-induced airway hyperresponsiveness to methacholine in asthmatics. Free Radic Biol Med. 2001;31:1442-7.

318. Stefanska J, Pawliczak R. Apocynin: molecular aptitudes. Mediators Inflamm. 2008;2008:106507.

319. Stolk J, Hiltermann TJ, Dijkman JH, Verhoeven AJ. Characteristics of the inhibition of NADPH oxidase activation in neutrophils by apocynin, a methoxy-substituted catechol. Am J Respir Cell Mol Biol. 1994;11:95-102.

320. Ximenes VF, Kanegae MPP, Rissato SR, Galhiane MS. The oxidation of apocynin catalyzed by myeloperoxidase: proposal for NADPH oxidase inhibition. Arch Biochem Biophys. 2007:457:134-41.

321. Petrônio MS, Zeraik ML, Fonseca LM, Ximenes VF. Apocynin: chemical and biophysical properties of a NADPH oxidase inhibitor. Molecules. 2013;18:2821-39.

322. Van den Worm E, Beukelman CJ, Van den Berg AJ, Kroes BH, Labadie RP, Van Dijk H. Effects of methoxylation of apocynin and analogs on the inhibition of reactive oxygen species production by stimulated human neutrophils. Eur J Pharmacol. 2001;433:225-30.

323. Stefanska J, Sarniak A, Wlodarczyk A, Sokolowska M, Pniewska E, Doniec Z, Nowak D, Pawliczak R. Apocynin reduces reactive oxygen species concentrations in exhaled breath condensate in asthmatics. Exp Lung Res. 2012;38:90-9.

324. O'Donnell VB, Smith GC, Jones OT. Involvement of phenyl radicals in iodonium inhibition of flavoenzymes. Mol Pharmacol. 1994;46:778-85.

325. Doussière J, Vignais PV. Diphenylene iodonium as an inhibitor of the NADPH oxidase complex of bovine neutrophils. Factors controlling the inhibitory potency of diphenylene iodonium in a cell-free system of oxidase activation. Eur J Biochem. 1992;208:61-71.

326. Stuehr DJ, Fasehun OA, Kwon NS, Gross SS, Gonzalez JA, Levi R, Nathan CF. Inhibition of macrophage and endothelial cell nitric oxide synthase by diphenyleneiodonium and its analogs. FASEB J. 1991;5:98-103.

327. Wyatt CN, Weir EK, Peers C. Diphenylene iodonium blocks K+ and Ca2+ currents in type I cells isolated from the neonatal rat carotid body. Neurosci Lett. 1994;172:63-6.

328. Nakamura Y, Tsuji K, Shuto M, Ogita K, Yoneda Y, Shimamoto K, Shibata T, Kataoka K. Protection by diphenyliodonium against glutamate neurotoxicity due to blocking of N-methyl-D-aspartate receptors. Neuroscience. 1997;76:459-66.

329. Aldieri E, Riganti C, Polimeni M, Gazzano E, Lussiana C, Campia I, Ghigo D. Classical inhibitors of NOX NAD(P)H oxidases are not specific. Curr Drug Metab. 2008:9:686-96.

330. Wang Q, Chu C-H, Oyarzabal E, Jiang L, Chen S-H, Wilson B, Qian L, Hong J-S. Subpicomolar diphenyleneiodonium inhibits microglial NADPH oxidase with high specificity and shows great potential as a therapeutic agent for neurodegenerative diseases. Glia. 2014;62:2034-43.

331. Williams HC, Griendling KK. NADPH oxidase inhibitors: new antihypertensive agents? J Cardiovasc Pharmacol. 2007;50:9-16.

332. Hirano K, Chen WS, Chueng AL, Dunne AA, Seredenina T, Filippova A, Ramachandran S, Bridges A, Chaudry L, Pettman G, et al. Discovery of GSK2795039, a novel small molecule NADPH oxidase two inhibitor. Antioxid Redox Signal. 2015;23:358-74

333. Gukovskaya AS, Vaquero E, Zaninovic V, Gorelick FS, Lusis AJ, Brennan ML, Holland S, Pandol SJ. Neutrophils and NADPH oxidase mediate intrapancreatic trypsin activation in murine experimental acute pancreatitis. Gastroenterology. 2002;122:974-84.

334. Stielow C, Catar RA, Muller G, Wingler K, Scheurer P, Schmidt HHHW, Morawietz $H$. Novel Nox inhibitor of oxLDL-induced reactive oxygen species formation in human endothelial cells. Biochem Biophys Res Commun. 2006;344:200-5.

335. Sun Q-A, Hess DT, Wang B, Miyagi M, Stamler JS. Off-target thiol alkylation by the NADPH oxidase inhibitor 3-benzyl-7-(2benzoxazolyl)thio-1,2,3-triazolo[4,5-d]pyrimidine (VAS2870). Free Radic Biol Med. 2012;52:1897-902

336. Sancho P, Fabregat I. The NADPH oxidase inhibitor VAS2870 impairs cell growth and enhances TGF- $\beta$-induced apoptosis of liver tumor cells. Biochem Pharmacol. 2011:81:917-24.

337. Niethammer P, Grabher C, Look AT, Mitchison TJ. A tissue-scale gradient of hydrogen peroxide mediates rapid wound detection in zebrafish. Nature. 2009;459:996-9.

338. ten Freyhaus $H$, Huntgeburth M, Wingler K, Schnitker J, Bäumer AT, Vantler M, Bekhite MM, Wartenberg M, Sauer H, Rosenkranz S. Novel Nox inhibitor VAS2870 attenuates PDGF-dependent smooth muscle cell chemotaxis, but not proliferation. Cardiovasc Res. 2006;71:331-41.
339. Wind S, Beuerlein K, Eucker T, Muller H, Scheurer P, Armitage ME, Ho H, Schmidt HH, Wingler K. Comparative pharmacology of chemically distinct NADPH oxidase inhibitors. Br J Pharmacol. 2010;161:885-98.

340. Gatto GJ, Ao Z, Kearse MG, Zhou M, Morales CR, Daniels E, Bradley BT, Goserud MT, Goodman KB, Douglas SA, et al. NADPH oxidase-dependent and -independent mechanisms of reported inhibitors of reactive oxygen generation. J Enzyme Inhib Med Chem. 2013;28:95-104.

341. Sedeek M, Callera G, Montezano A, Gutsol A, Heitz F, Szyndralewiez C, Page $P$, Kennedy CRJ, Burns KD, Touyz RM, Hébert RL. Critical role of Nox4-based $\mathrm{NADPH}$ oxidase in glucose-induced oxidative stress in the kidney: implications in type 2 diabetic nephropathy. Am J Physiol Renal Physiol. 2010;299:1348-58

342. Laleu B, Gaggini F, Orchard M, Fioraso-Cartier L, Cagnon L, HoungninouMolango S, Gradia A, Duboux G, Merlot C, Heitz F, et al. First in class, potent, and orally bioavailable NADPH oxidase isoform four (Nox4) inhibitors for the treatment of idiopathic pulmonary fibrosis. J Med Chem. 2010;53:7715-30.

343. Schildknecht S, Weber A, Gerding HR, Pape R, Robotta M, Drescher M, Marquardt A, Daiber A, Ferger B, Leist M. The NOX1/4 inhibitor GKT136901 as selective and direct scavenger of peroxynitrite. Curr Med Chem. 2013;21:365-76.

344. Anvari E, Wikstrom P, Walum E, Welsh N. The novel NADPH oxidase four inhibitor GLX351322 counteracts glucose intolerance in high-fat diet-treated C57BL/6 mice. Free Radic Res. 2015;49:1308-18.

345. de Franciscis V, Esposito CL, Catuogno S, Cellai L, Cerchia L. Aptamers as innovative diagnostic and therapeutic agents in the central nervous system. CNS Neurol Disord Drug Targets. 2009;8:393-401.

346. McConnell EM, Holahan MR, DeRosa MC. Aptamers as promising molecular recognition elements for diagnostics and therapeutics in the central nervous system. Nucleic Acid Ther. 2014;24:388-404.

347. Sriramoju B, Kanwar R, Veedu RN, Kanwar JR. Aptamer-targeted oligonucleotide theranostics: a smarter approach for brain delivery and the treatment of neurological diseases. Curr Top Med Chem. 2015;15:1115-24.

348. Zhou J, Bobbin ML, Burnett JC, Rossi JJ. Current progress of RNA aptamerbased therapeutics. Front Genet. 2012;3:234

349. Cheng C, Chen YH, Lennox KA, Behlke MA, Davidson BL. In vivo SELEX for identification of brain-penetrating aptamers. Mol Ther Nucleic Acids. 2013;2:e67.

350. Zhou J, Rossi JJ. Cell-specific aptamer-mediated targeted drug delivery. Oligonucleotides. 2011;21:1-10

351. Blake CM, Wang H, Laskowitz DT, Sullenger BA. A reversible aptamer improves outcome and safety in murine models of stroke and hemorrhage. Oligonucleotides. 2011;21:11-9.

352. Gopinath SC, Hayashi K, Kumar PK. Aptamer that binds to the gD protein of herpes simplex virus one and efficiently inhibits viral entry. J Virol. 2012;86: 6732-44.

353. Brandes RP, Weissmann N, Schröder K. Nox family NADPH oxidases: molecular mechanisms of activation. Free Radic Biol Med. 2014;76:208-26.

354. Osman AM, Porritt MJ, Nilsson M, Kuhn HG. Long-term stimulation of neural progenitor cell migration after cortical ischemia in mice. Stroke. 2011:42:3559-65.

355. Garrido-Urbani S, Jemelin S, Deffert C, Carnesecchi S, Basset O, Szyndralewiez C, Heitz F, Page P, Montet X, Michalik L, et al. Targeting vascular NADPH oxidase one blocks tumor angiogenesis through a PPARalpha mediated mechanism. PLoS One. 2011;6:e14665.

356. Wang J, Hong Z, Zeng C, Yu Q, Wang H. NADPH oxidase four promotes cardiac microvascular angiogenesis after hypoxia/reoxygenation in vitro. Free Radic Biol Med. 2014;69:278-88.

357. Usui T, Naruo A, Okada M, Hayabe Y, Yamawaki H. Brain-derived neurotrophic factor promotes angiogenic tube formation through generation of oxidative stress in human vascular endothelial cells. Acta Physiol (Oxf). 2014;211:385-94.

358. Kishida KT, Hoeffer CA, Hu D, Pao M, Holland SM, Klann E. Synaptic plasticity deficits and mild memory impairments in mouse models of chronic granulomatous disease. Mol Cell Biol. 2006;26:5908-20.

359. Ago T, Kitazono T, Kuroda J, Kumai Y, Kamouchi M, Ooboshi H, Wakisaka M, Kawahara T, Rokutan K, Ibayashi S, lida M. NAD(P)H oxidases in rat basilar arterial endothelial cells. Stroke. 2005;36:1040-6.

360. Frey RS, Ushio-Fukai M, Malik AB. NADPH oxidase-dependent signaling in endothelial cells: role in physiology and pathophysiology. Antioxid Redox Signal. 2009;11:791-810.

361. Guggilam A, Haque M, Kerut EK, Mcllwain E, Lucchesi P, Seghal I, Francis J. TNF-alpha blockade decreases oxidative stress in the paraventricular nucleus and attenuates sympathoexcitation in heart failure rats. Am J Physiol Heart Circ Physiol. 2007;293:H599-609. 
362. McCrann DJ, Eliades A, Makitalo M, Matsuno K, Ravid K. Differential expression of NADPH oxidases in megakaryocytes and their role in polyploidy. Blood. 2009;114:1243-9.

363. Coyoy A, Valencia A, Guemez-Gamboa A, Morán J. Role of NADPH oxidase in the apoptotic death of cultured cerebellar granule neurons. Free Radic Biol Med. 2008;45:1056-64.

364. Cristovao AC, Choi DH, Baltazar G, Beal MF, Kim YS. The role of NADPH oxidase one-derived reactive oxygen species in paraquat-mediated dopaminergic cell death. Antioxid Redox Signal. 2009;11:2105-18.

365. Paravicini TM, Chrissobolis S, Drummond GR, Sobey CG. Increased NADPH-oxidase activity and Nox4 expression during chronic hypertension is associated with enhanced cerebral vasodilatation to NADPH in vivo. Stroke. 2004;35:584-9.

366. Bayraktutan U, Blayney L, Shah AM. Molecular characterization and localization of the $\mathrm{NAD}(\mathrm{P}) \mathrm{H}$ oxidase components gp91-phox and p22-phox in endothelial cells. Arterioscler Thromb Vasc Biol. 2000; 20:1903-11.

367. Borregaard N. The respiratory burst of phagocytosis: biochemistry and subcellular localization. Immunol Lett. 1985;11:165-71.

368. Krijnen PA, Meischl C, Hack CE, Meijer CJ, Visser CA, Roos D, Niessen HW Increased Nox2 expression in human cardiomyocytes after acute myocardial infarction. J Clin Pathol. 2003:56:194-9.

369. Mohazzab HK, Kaminski PM, Wolin MS. Lactate and PO2 modulate superoxide anion production in bovine cardiac myocytes: potential role of NADH oxidase. Circulation. 1997;96:614-20.

370. Geiszt M, Kopp JB, Varnai P, Leto TL. Identification of renox, an NAD(P)H oxidase in kidney. Proc Natl Acad Sci U S A. 2000;97:8010-4.

371. Christophi GP, Rong R, Holtzapple PG, Massa PT, Landas SK. Immune markers and differential signaling networks in ulcerative colitis and Crohn's disease. Inflamm Bowel Dis. 2012;18:2342-56.

372. Reinehr R, Becker S, Eberle A, Grether-Beck S, Haussinger D. Involvement of NADPH oxidase isoforms and Src family kinases in CD95-dependent hepatocyte apoptosis. J Biol Chem. 2005;280:27179-94.

373. Masamune A, Watanabe T, Kikuta K, Satoh K, Shimosegawa T. NADPH oxidase plays a crucial role in the activation of pancreatic stellate cells. Am J Physiol Gastrointest Liver Physiol. 2008;294:G99-G108.

374. Serrano F, Kolluri NS, Wientjes FB, Card JP, Klann E. NADPH oxidase immunoreactivity in the mouse brain. Brain Res. 2003;988:193-8.

375. Bruce-Keller AJ, White CL, Gupta S, Knight AG, Pistell PJ, Ingram DK, Morrison CD, Keller JN. NOX activity in brain aging: exacerbation by high fat diet. Free Radic Biol Med. 2010;49:22-30.

376. Hernandes MS, D'Avila JC, Trevelin SC, Reis PA, Kinjo ER, Lopes LR, CastroFaria-Neto HC, Cunha FQ, Britto LR, Bozza FA. The role of Nox2-derived ROS in the development of cognitive impairment after sepsis. J Neuroinflammation. 2014;11:36

377. McCann SK, Dusting GJ, Roulston CL. Early increase of Nox4 NADPH oxidase and superoxide generation following endothelin-1-induced stroke in conscious rats. J Neurosci Res. 2008;86:2524-34.

378. Guemez-Gamboa A, Estrada-Sanchez AM, Montiel T, Paramo B, Massieu L, Moran J. Activation of NOX2 by the stimulation of ionotropic and metabotropic glutamate receptors contributes to glutamate neurotoxicity in vivo through the production of reactive oxygen species and calpain activation. J Neuropathol Exp Neurol. 2011:70:1020-35.

379. Zawada WM, Banninger GP, Thornton J, Marriott B, Cantu D, Rachubinski AL, Das M, Griffin WST, Jones SM. Generation of reactive oxygen species in 1-methyl-4-phenylpyridinium (MPP+) treated dopaminergic neurons occurs as an NADPH oxidase-dependent two-wave cascade. J Neuroinflammation. 2011;8:129.

380. Qin L, Liu Y, Hong JS, Crews FT. NADPH oxidase and aging drive microglial activation, oxidative stress, and dopaminergic neurodegeneration following systemic LPS administration. Glia. 2013;61:855-68.

381. Ye S, Zhong H, Yanamadala S, Campese VM. Oxidative stress mediates the stimulation of sympathetic nerve activity in the phenol renal injury model of hypertension. Hypertension. 2006:48:309-15.

382. Lob HE, Schultz D, Marvar PJ, Davisson RL, Harrison DG. Role of the NADPH oxidases in the subfornical organ in angiotensin I-induced hypertension. Hypertension. 2013;61:382-7.

383. Lelli A, Gervais A, Colin C, Cheret C, RuizdeAlmodovar C, Carmeliet P, Krause $\mathrm{KH}$, Boillee S, Mallat M. The NADPH oxidase Nox2 regulates VEGFR1/CSF-1Rmediated microglial chemotaxis and promotes early postnatal infiltration of phagocytes in the subventricular zone of the mouse cerebral cortex. Glia. 2013;61:1542-55.
384. Wang G, Anrather J, Huang J, Speth RC, Pickel VM, ladecola C. NADPH oxidase contributes to angiotensin II signaling in the nucleus tractus solitarius. J Neurosci. 2004;24:5516-24.

385. Mukherjea D, Whitworth CA, Nandish S, Dunaway GA, Rybak LP, Ramkumar $V$. Expression of the kidney injury molecule one in the rat cochlea and induction by cisplatin. Neuroscience. 2006;139:733-40.

386. Zhang X, Shan P, Jiang G, Cohn L, Lee PJ. Toll-like receptor four deficiency causes pulmonary emphysema. J Clin Invest. 2006;116:3050-9.

387. Ruwanpura SM, McLeod L, Lilja AR, Brooks G, Dousha LF, Seow HJ, Bozinovski S, Vlahos R, Hertzog PJ, Anderson GP, Jenkins BJ. Non-essential role for TLR2 and its signaling adaptor Mal/TIRAP in preserving normal lung architecture in mice. PLoS One. 2013;8:e78095.

388. Chabrashvili T, Tojo A, Onozato ML, Kitiyakara C, Quinn MT, Fujita T, Welch WJ, Wilcox CS. Expression and cellular localization of classic NADPH oxidase subunits in the spontaneously hypertensive rat kidney. Hypertension. 2002; 39:269-74.

389. Sorescu D, Weiss D, Lassegue B, Clempus RE, Szocs K, Sorescu GP, Valppu L, Quinn MT, Lambeth JD, Vega JD, et al. Superoxide production and expression of nox family proteins in human atherosclerosis. Circulation. 2002;105:1429-35

390. Szocs K, Lassegue B, Sorescu D, Hilenski LL, Valppu L, Couse TL, Wilcox JN, Quinn MT, Lambeth JD, Griendling KK. Upregulation of Nox-based NAD(P)H oxidases in restenosis after carotid injury. Arterioscler Thromb Vasc Biol. 2002;22:21-7.

391. Dhaunsi GS, Paintlia MK, Kaur J, Turner RB. NADPH oxidase in human lung fibroblasts. J Biomed Sci. 2004;11:617-22.

392. Sturrock A, Cahill B, Norman K, Huecksteadt TP, Hill K, Sanders K, Karwande SV, Stringham JC, Bull DA, Gleich M, et al. Transforming growth factor-beta1 induces Nox4 NAD(P)H oxidase and reactive oxygen species-dependent proliferation in human pulmonary artery smooth muscle cells. Am J Physiol Lung Cell Mol Physiol. 2006;290:L661-73.

393. Mittal M, Roth M, Konig P, Hofmann S, Dony E, Goyal P, Selbitz AC, Schermuly RT, Ghofrani HA, Kwapiszewska G, et al. Hypoxia-dependent regulation of nonphagocytic NADPH oxidase subunit NOX4 in the pulmonary vasculature. Circ Res. 2007;101:258-67.

394. Fu P, Mohan V, Mansoor S, Tiruppathi C, Sadikot RT, Natarajan V. Role of nicotinamide adenine dinucleotide phosphate-reduced oxidase proteins in Pseudomonas aeruginosa-induced lung inflammation and permeability. Am J Respir Cell Mol Biol. 2013;48:477-88.

395. Yang S, Madyastha P, Bingel S, Ries W, Key L. A new superoxide-generating oxidase in murine osteoclasts. J Biol Chem. 2001;276:5452-8.

396. Goyal R, Yellon SM, Longo LD, Mata-Greenwood E. Placental gene expression in a rat 'model' of placental insufficiency. Placenta. 2010;31:568-75.

397. Vallet $P$, Charnay $Y$, Steger K, Ogier-Denis E, Kovari E, Herrmann F, Michel JP, Szanto I. Neuronal expression of the NADPH oxidase NOX4, and its regulation in mouse experimental brain ischemia. Neuroscience. 2005:132:233-8

398. Infanger DW, Cao X, Butler SD, Burmeister MA, Zhou Y, Stupinski JA, Sharma RV, Davisson RL. Silencing nox4 in the paraventricular nucleus improves myocardial infarction-induced cardiac dysfunction by attenuating sympathoexcitation and periinfarct apoptosis. Circ Res. 2010;106:1763-74.

399. Holterman CE, Thibodeau JF, Towaij C, Gutsol A, Montezano AC, Parks RJ, Cooper ME, Touyz RM, Kennedy CR. Nephropathy and elevated BP in mice with podocyte-specific NADPH oxidase five expression. J Am Soc Nephrol. 2014;25:784-97.

400. BelAiba RS, Djordjevic T, Petry A, Diemer K, Bonello S, Banfi B, Hess J, Pogrebniak A, Bickel C, Gorlach A. NOX5 variants are functionally active in endothelial cells. Free Radic Biol Med. 2007;42:446-59.

401. Guzik TJ, Chen W, Gongora MC, Guzik B, Lob HE, Mangalat D, Hoch N, Dikalov S, Rudzinski P, Kapelak B, et al. Calcium-dependent NOX5 nicotinamide adenine dinucleotide phosphate oxidase contributes to vascular oxidative stress in human coronary artery disease. J Am Coll Cardiol. 2008;52:1803-9.

402. Cui $X L$, Chang B, Myatt L. Expression and distribution of NADPH oxidase isoforms in human myometrium-role in angiotensin II-induced hypertrophy. Biol Reprod. 2010;82:305-12.

403. Geiszt M, Witta J, Baffi J, Lekstrom K, Leto TL. Dual oxidases represent novel hydrogen peroxide sources supporting mucosal surface host defense. FASEB J. 2003;17:1502-4.

404. Quadrato G, Elnaggar MY, Di Giovanni S. Adult neurogenesis in brain repair: cellular plasticity vs. cellular replacement. Front Neurosci. 2014;8:17. 
405. Ming GL, Song $H$. Adult neurogenesis in the mammalian brain: significant answers and significant questions. Neuron. 2011;70:687-702.

406. El Hassani RA, Benfares N, Caillou B, Talbot M, Sabourin JC, Belotte V, Morand S, Gnidehou S, Agnandji D, Ohayon R, et al. Dual oxidase two is expressed all along the digestive tract. Am J Physiol Gastrointest Liver Physiol. 2005;288:933-42.

407. Park L, Zhou P, Pitstick R, Capone C, Anrather J, Norris EH, Younkin L, Younkin S, Carlson G, McEwen BS, ladecola C. Nox2-derived radicals contribute to neurovascular and behavioral dysfunction in mice overexpressing the amyloid precursor protein. Proc Natl Acad Sci U S A. 2008;105:1347-52.

408. Qin B, Cartier L, Dubois-Dauphin M, Li B, Serrander L, Krause K-H. A key role for the microglial NADPH oxidase in APP-dependent killing of neurons. Neurobiol Aging. 2006;27:1577-87.

409. Kahles T, Kohnen A, Heumueller S, Rappert A, Bechmann I, Liebner S, Wittko IM, Neumann-Haefelin T, Steinmetz H, Schroeder K, Brandes RP. NADPH oxidase Nox1 contributes to ischemic injury in experimental stroke in mice. Neurobiol Dis. 2010;40:185-92.

410. Doverhag C, Keller M, Karlsson A, Hedtjarn M, Nilsson U, Kapeller E, Sarkozy G, Klimaschewski L, Humpel C, Hagberg H, et al. Pharmacological and genetic inhibition of NADPH oxidase does not reduce brain damage in different models of perinatal brain injury in newborn mice. Neurobiol Dis. 2008;31:133-44.

411. Suh SW, Shin BS, Ma H, Van Hoecke M, Brennan AM, Yenari MA, Swanson RA. Glucose and NADPH oxidase drive neuronal superoxide formation in stroke. Ann Neurol. 2008:64:654-63.

412. Lo W, Bravo T, Jadhav V, Titova E, Zhang JH, Tang J. NADPH oxidase inhibition improves neurological outcomes in surgically-induced brain injury. Neurosci Lett. 2007;414:228-32.

\section{Submit your next manuscript to BioMed Central and we will help you at every step:}

- We accept pre-submission inquiries

- Our selector tool helps you to find the most relevant journal

- We provide round the clock customer support

- Convenient online submission

- Thorough peer review

- Inclusion in PubMed and all major indexing services

- Maximum visibility for your research

Submit your manuscript at www.biomedcentral.com/submit 